\title{
Development and Formation Mechanism of the Southeast Asian Winter Heavy Rainfall Events around the South China Sea. Part I: Formation and Propagation of Cold Surge Vortex*
}

\author{
TSING-Chang Chen AND JenQ-DAR TSAY \\ Department of Geological and Atmospheric Sciences, Iowa State University, Ames, Iowa \\ Jun Matsumoto \\ Department of Geography, Tokyo Metropolitan University, Tokyo, and Research Institute for Global Change, \\ JAMSTEC, Yokosuka, Japan \\ JORDAN ALPERT \\ Environmental Modeling Center, National Centers for Environmental Prediction, NOAA/Center for Weather and \\ Climate Prediction, College Park, Maryland
}

(Manuscript received 26 February 2014, in final form 25 September 2014)

\begin{abstract}
Examination of the development of cold season heavy rainfall/flood (HRF) events around the South China Sea (SCS) from their parent cold surge vortices (CSVs) shows three new development processes. First, the formation mechanism of the parent CSV of an HRF event [CSV(HRF)] has a preference as to geographic location, flow type of the cold surge inside the SCS, and time of day. The surface trough east of the Philippines, Taiwan, and southern Japan island chain in late fall and the near-equator trough across Borneo in winter facilitate the CSV(HRF) formation in two regions - the vicinity of the Philippines and Borneo. The formation of the Philippine (Borneo) CSV(HRF) occurs at 0600 UTC (0000 UTC) with involvement from the Philippine Sea (PHS)type (SCS type) of cold surge flow. Second, the flow type of the cold surge determines the CSV(HRF) propagation across the South China Sea. The PHS-type (SCS type) facilitates (hinders) the CSV(HRF) westward propagation. This occurs because the easterly (northerly) flow is greater than (less than) the northerly (easterly) flow at the maximum isotach location of the cold surge flow associated with CSV(HRF) and is centered east of the demarcation line for propagation. This flow-type contrast is substantiated by the vorticity budget analysis for $\mathrm{CSV}(\mathrm{HRF})$. The positive 925-hPa vorticity tendency is located west of (coincident with) the 925-hPa vorticity center for the PHS-type (SCS type) of cold surge. Third, the CSV(HRF) development into a HRF event is achieved through multiple interactions of former vortices with sequential cold surges across the South China Sea. The first two CSV(HRF) development processes are reported herein; the last process is presented in Part II.
\end{abstract}

\section{Introduction}

The major cold season weather/climate system in Southeast Asia, particularly the heavy rainfall flood (HRF) event, is developed by the midlatitude-tropic

\footnotetext{
* Supplemental information related to this paper is available at the Journals Online website: http://dx.doi.org/10.1175/JCLI-D-14-00170.s1.

Corresponding author address: Tsing-Chang (Mike) Chen, Atmospheric Science Program, Department of Geological and Atmospheric Sciences, 3010 Agronomy Hall, Iowa State University, Ames, IA 50011.

E-mail: tmchen@iastate.edu
}

interaction through the East Asian cold surge. The impact of this interaction is reflected by the seasonal variation of the rainfall climatology over the countries around both sides of the South China Sea, indicated by World Meteorological Organization (WMO) surface stations (Fig. 1a, red dots). Rainfall along these two coastal lines exhibits a southward seasonal migration from the north $\left(15^{\circ}-20^{\circ} \mathrm{N}\right)$ in late fall to south of the equator in winter. This is shown by rainfall centers along each coastal line in the rainfall latitude-time $(y-t)$ diagram: 1) central Vietnam, peninsular Malaysia, and Sumatra-Java along the west coast of the South China Sea (SCS) (Fig. 1b) and 2) the northern Philippines, 


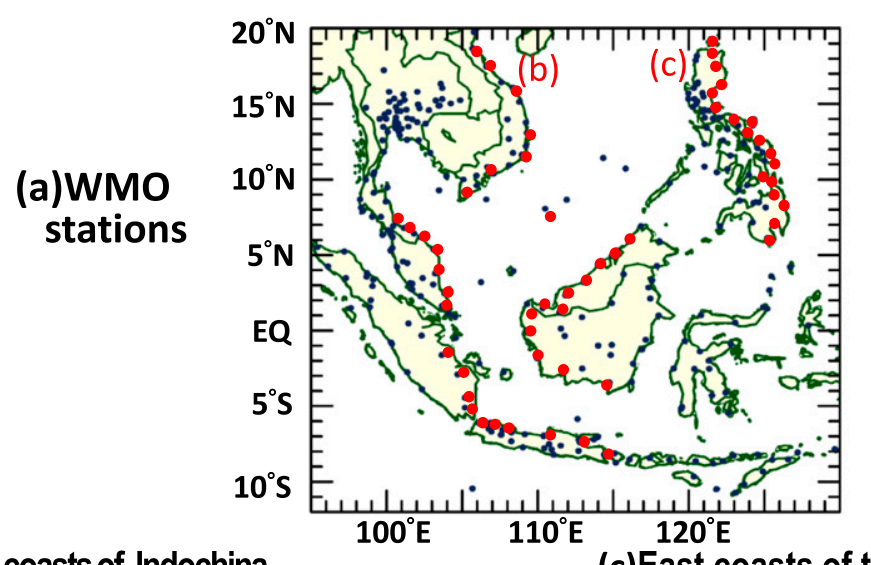

(b)East coasts of Indochina peninsular Malaysia, Sumatra, Java

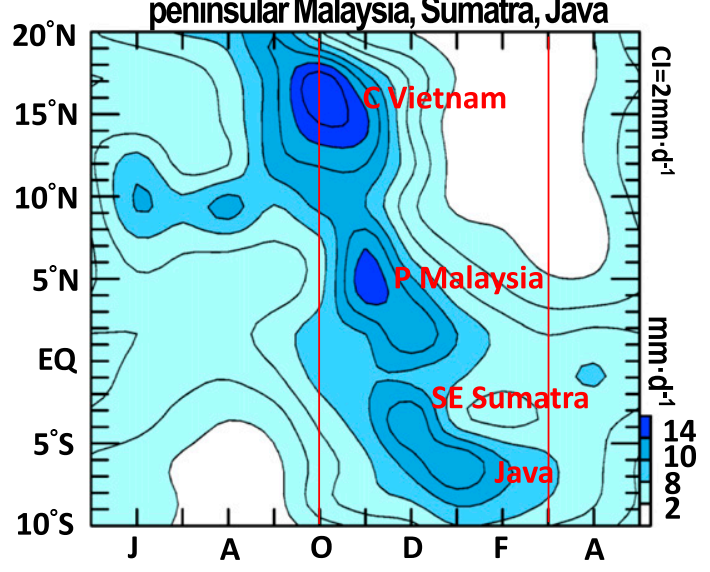

(c)East coasts of the Philippines and west coast of Borneo

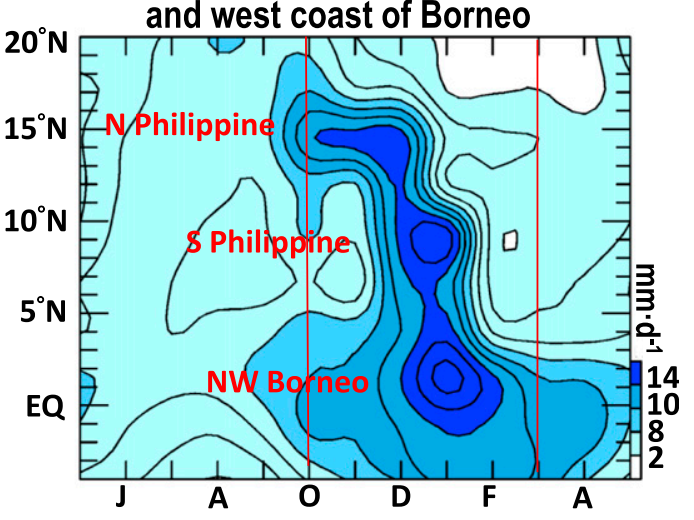

FIG. 1. (a) WMO surface stations (dark blue and red dots) in Southeast Asia, but only rainfall measurements of stations marked with red dots are used to make the rainfall $y-t$ diagrams along both sides of the South China Sea. The seasonal evolution of rainfall along (b) the east coast of Vietnam, peninsular Malaysia, and Sumatra-Java, and (c) the east coast of the Philippines and the west coast of Borneo.

Mindanao, and northwestern Borneo west of the SCS (Fig. 1c). These phenomena were observed and analyzed by our recent studies; the rainfall centers in central Vietnam (Chen et al. 2012a) and Malaysia (Chen et al. 2013a,b) are primarily produced by HRF events identified by the Dartmouth Flood Observatory (DFO; DFO 2013; http://flood observatory.colorado.edu/) for the last few decades. Shown in Fig. 2 are 181 HRF events in Southeast Asia during the 1979-2012 period: 83 events occurred in Indochina and Borneo during 1979-2012, and 98 events occurred in the Philippines and SumatraJava during 1992-2012.

Observed by Cheang (1977), the winter rainfall in tropical Southeast Asia is primarily produced by the intensified equator vortex in the presence of the northeast Asian cold surge flow. This observation was confirmed by the cold surge vortex (CSV; formed by the interaction between the easterly wave and the cold surge flow) in tropical Southeast Asia by Chen (2002) in search of the forcing mechanism of the trans-Pacific winter shortwave train. After an examination of the environment conducive to the occurrence of heavy rainfall vortices in central Vietnam, Yokoi and Matsumoto (2008) claimed the coexistence of a tropical depression-like vortex and a cold surge flow is a required condition. To obtain a more in-depth understanding of the formation mechanism of the HRF cyclone and/or noncyclone event (cyclone/event) in central Vietnam, Chen et al. (2012a) recently explored the synoptic development of this mechanism from the perspective of midlatitude-tropic interactions through the cold surge flow involved with the formation and development of the parent CSV. Four identified synoptic features pertaining to the present study are listed:

1) The parent CSV of an HRF cyclone/event, herein called $\operatorname{CSV}(\mathrm{HRF})$, is formed by the interactions between an easterly wave and the East Asian cold surge flow in the vicinity of the Philippines or between the East Asian cold surge flow and Borneo orography. 
2) Basic characteristics (including speed, size, and rainfall) of CSVs, which evolve into HRF cyclones/ events, are well distinguishable one day after their formation against the nondeveloping CSV.

3) Occurrences of the central Vietnam HRF events synchronize with those of the northwestern Pacific explosive cyclones.

4) Indicated by the $850-\mathrm{hPa}$ zonal wind, maximum speed for the HRF cyclone/event easterlies, tropical trade easterlies from the North Pacific anticyclone, and westerlies from the northwestern Pacific explosive cyclone occur simultaneously.

Although synoptic features about the formation of CSV(HRF) and their development into HRF cyclones/ events have been documented by our previous studies, the formation locations, propagation properties (inferred from their trajectories), and the development process of CSV(HRF) into HRF cyclones/events (shown in Fig. 2) lead to the following issues regarding this development mechanism:

1) The CSV(HRF) formation only occurs in two regions - the vicinity of the Philippines and Borneo. The interaction of cold surge flow with easterly waves or orography should not be restricted only to these two regions. So, what causes the geographic preference of CSV(HRF) formation? Some special environmental conditions restrict the $\operatorname{CSV}(\mathrm{HRF})$ formation in these two regions.

2) Observed by Chen et al. (2013a), the peninsular Malaysia HRF events are developed by the westward-propagating parent CSV(HRF) from both the vicinity of the Philippines and Borneo. However, the Borneo HRF events evolve from their in situ parent $\operatorname{CSV}(\mathrm{HRF})$ that stagnate in Borneo. The westward propagation of CSV(HRF) is determined by the cold surge flow type, as classified by Compo et al. (1999) — the SCS and the Philippine Sea (PHS) types. We will test whether this hypothesized mechanism of the CSV(HRF) propagation property is applied to all CSV(HRF) around the South China Sea.

3) The basic characteristics (size, speed, and rainfall) of HRF cyclones/events are much larger/stronger than their parent CSV(HRF). So far, the development mechanism of these CSV(HRF) into HRF cyclones/ events has not been explored or understood. Both formations of CSV(HRF) and HRF cyclone/event are involved with interactions of CSV(HRF) with different cold surge flows. The development time and traveling distance between formation locations of CSV(HRF) and HRF events may be $2-10$ days between the equator and $25^{\circ} \mathrm{N}$. Therefore, we may question if some HRF cyclones/events develop from their parent CSV(HRF) by interacting with more or less than two different cold surge flows.

The large contribution of HRF events to the rainfall centers west of the South China Sea (Fig. 1) suggests that other rainfall centers around the South China Sea are also primarily formed by HRF events. Thus, an effort is made in this study to explore the three aforementioned issues related to the development mechanism of CSV(HRF) into HRF events around the South China Sea. The results will be presented in two parts; the first two issues are addressed here (the present paper) and the third issue is reported in Chen et al. (2015, hereafter Part II). The first part of this study is structured and reported in the following manner. Data used in the study are described in section 2. Elements of the large-scale monsoon circulation conducive to the CSV(HRF) formation are portrayed in section 3. Synoptic conditions of CSV(HRF) formation and development into a HRF cyclone/event in rainfall centers along both coasts of the South China Sea are shown in section 4. In this section, confirmation of the CSV(HRF) formation mechanisms is made with the synoptic analysis. Statistics for the synoptic features crucial to the CSV(HRF) formation mechanism are presented in section 5. The propagation properties of CSV(HRF) and the mechanism regulating these properties substantiated by the vorticity budget analysis are illustrated in section 6 . A summary of the results presented in this study, concluding remarks, and suggestions for future studies are offered in section 7 .

\section{Data and identification of a CSV(HRF), HRF event, northwestern Pacific explosive cyclone, and shallow surface trough}

\section{a. Data}

Datasets used for the present study are updated and expanded from those used in our previous analyses for the cold-season rainfall in Vietnam (Chen et al. 2012a) and Malaysia (Chen et al. 2013a, their Table 1) in two ways: 1) the length of the data coverage period and 2) the domain. First, the data period of 1979-2008 for the cold season rainfall studies of Vietnam and Malaysia is expanded to include 2012, and second, the data domain of Chen et al. (2012a, 2013a) is retained and expanded as described below.

\section{1) RETENTION}

- Regional rainfall and satellite data from the Asian Precipitation-Highly-Resolved Observational Data 

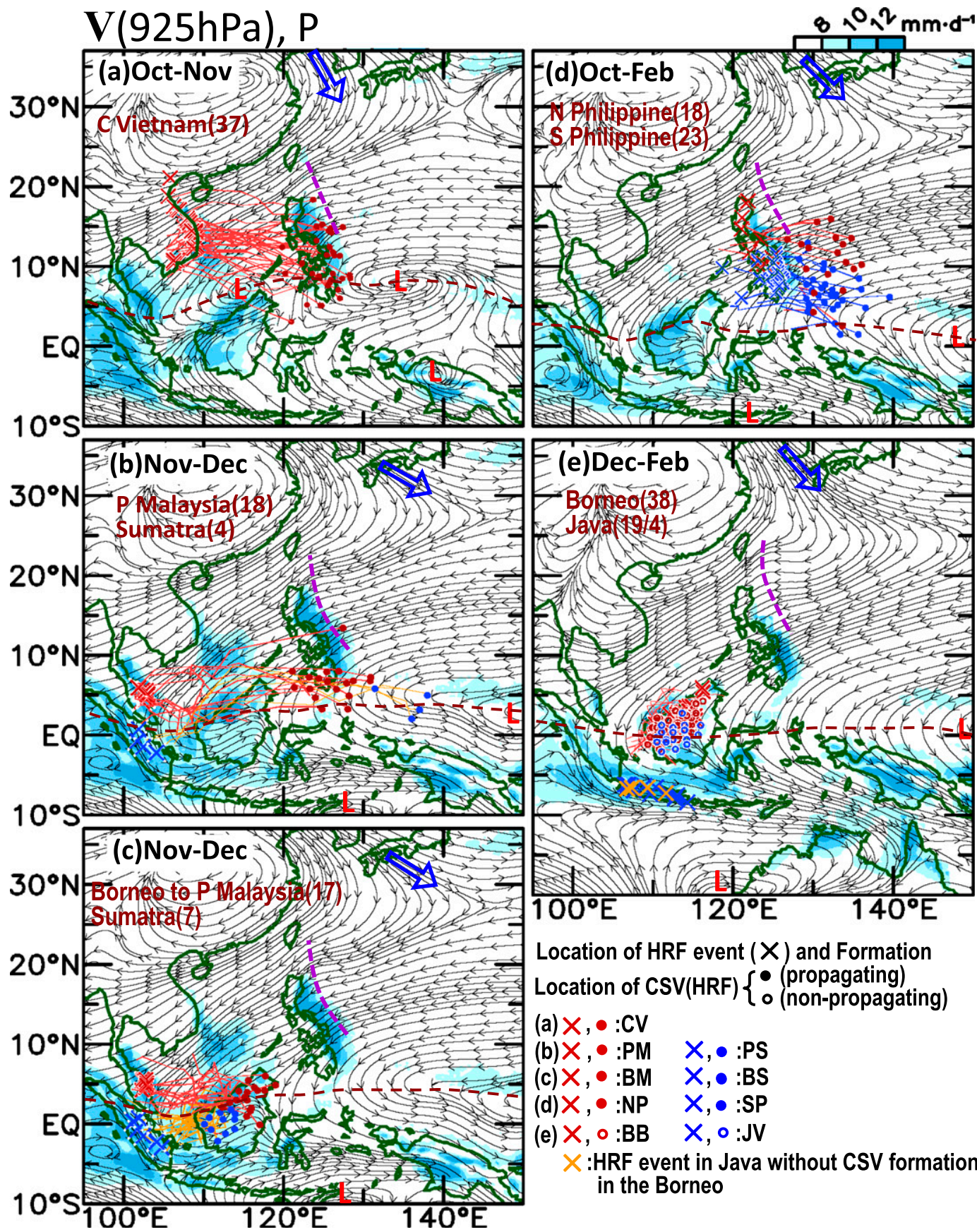

Location of HRF event $(X)$ and Formation Location of CSV(HRF) $\left\{\begin{array}{l}\bullet \text { (propagating) } \\ \circ \text { (non-propagating) }\end{array}\right.$
(a) $X, \bullet: C V$
(b) $X, \bullet: P M \quad X, \bullet: P S$
(c) $X, \bullet: B M \quad X, \bullet: B S$
(d) $X, \bullet: N P \quad X, \bullet: S P$
(e) $X, \circ: B B \quad X, \circ: J V$

$X: H R F$ event in Java without CSV formation in the Borneo

FIG. 2. Formation locations of propagating CSV(HRF) (solid red or blue dots), nonpropagating CSV(HRF) (open red or blue circles), HRF event (crosses), CSV(HRF) trajectory (thin red line), and precipitation (blue) superimposed on the 925-hPa streamline chart, for (a) October-November, (b), (c) November-December, (d) OctoberFebruary, and (e) December-February. CSV(HRF) reaching (stagnated) the west (east) side of the South China Sea are shown on the left (right). Red thick dashed lines and purple thick dashed lines mark the near-equator trough and the island-chain trough, respectively. Countries affected by HRF events and numbers of HRF events in these countries are shown in the upper left corner of each panel. Formation location of CSV(HRF) and occurrence location of $\mathrm{HRF}$ event are marked by dots and crosses in red or blue for different regions indicated by abbreviations provided in the bottom right corner. Location of Borneo CSV(HRF) related to Borneo and Java HRF HRFs are marked by red and blue open circles in (e). 
Integration Toward Evaluation of Water Resources (APHRODITE, v1204R1) rainfall over the Asian land area and the regional blackbody temperature $T_{\mathrm{BB}}$ measured by the Geostationary Meteorological Satellite (GMS) series, GOES-9, and Multifunction Transport Satellite (MTSAT) series;

- global rainfall and rainfall proxy from TRMM, GPI, GPCP, and MSU;

- global reanalyses/initial analyses from NCEP GFS, ERA-Interim, and GEOS-5, and NOAA OISSTv2 for global sea surface temperature;

- daily surface maps issued by NCEP Service Records Retention System (SRRS), JMA, and the Thai Meteorological Department (TMD);

- DFO HRF events over Vietnam and Malaysia; and

- The northwestern Pacific explosive cyclones identified with the Sanders-Gyakum $24 \mathrm{hPa} \mathrm{day}^{-1}$ criterion and its synchronous formation with the occurrence of HRF events of central Vietnam and Malaysia.

\section{2) EXPANSION}

- The WMO surface observations in Vietnam, Malaysia, the Philippines, and Indonesia around the South China Sea are analyzed;

- the Australian Bureau of Meteorology (BoM) daily surface maps are also utilized to verify the synoptic development of CSV(HRF) and HRF events over southeastern Sumatra and Java depicted by daily maps of other operational agencies;

- the DFO HRF events include southeastern Sumatra, Java, and the Philippines, and all HRF events around the South China Sea analyzed are verified with the International Emerging Disaster Database (EM-DAT 2013); and

- the analysis of HRF events covers seven rainfall centers around the South China Sea, and the identified northwestern Pacific explosive cyclones related to the HRF events of the Philippines and Indonesia are included.

A summary of the information (source, resolution, domain, and period) of both the retained and expanded datasets is presented in Table 1 .

\section{b. Identification of the cold surge vortex, cold surge type, and relevant synoptic elements}

\section{1) HRF COLD SURGE VORTEX}

About $60 \%$ of the cold season rainfall over central Vietnam (Chen et al. 2012a) and Malaysia (including peninsular Malaysia and Borneo; Chen et al. 2013a,b) is produced by HRF cyclones/events. These cyclones/ events develop from the Philippine and Borneo CSV(HRF).
The procedure that identifies these CSV(HRF) in the present study is updated from our previous studies with new findings from the CSV formation mechanisms presented in sections 4 and 5:

- Step 1: As shown in the 925-hPa streamline chart (Fig. 2), the "Philippine CSV" is a closed vortex formed in the vicinity of the Philippines by the interactions of an easterly wave with the PHS-type cold surge flow and the island-chain trough (defined in section 3). Emerging from the 925 -hPa streamline chart, the "Borneo CSV" is a closed vortex over northwestern Borneo formed by the interaction of the SCS-type cold surge flow with the cyclonic shear flow around the nearequator trough and Borneo orography.

- Step 2: The identified CSVs are verified against available operational surface analyses-the NCEP 6-h SRRS charts, and surface analysis charts for JMA, TMD, and BoM.

- Step 3: The preferred formation time of the Philippine CSV(HRF) is 0600 UTC (between 0300 and 0900 UTC), whereas that for the Borneo CSV(HRF) is 0000 UTC (between 2300 and 2400 UTC).

- Step 4: A backtracking approach is adopted to trace all HRF cyclones/events identified by the DFO, verified by EM-DAT, from their occurrence locations to the formation locations of their parent CSVs.

\section{2) COLD SURGE TYPE}

To explore its impact on the local weather system, cold surge is often defined with surface pressure increase $\left(\Delta p_{s}\right)$, surface temperature drop $\left(\Delta T_{s}\right)$, and the passage of surface wind surge measured at a selected location. For the current study, the major concern is the flow type of cold surge related to two major issues: 1) the CSV formation and 2) the CSV(HRF) propagation property.

- Issue 1: The flow type of cold surge related to the CSV formation.

Compo et al. (1999) traced the preferred paths and classified the East Asian cold surges into the PHS and the SCS types. Based on spectral analyses of surface pressure and $850-\mathrm{hPa}$ zonal wind, they selected two base points to depict the cold surge flow pattern with a regression approach: $20^{\circ} \mathrm{N}, 140^{\circ} \mathrm{E}$ as the PHS base point and $15^{\circ} \mathrm{N}, 115^{\circ} \mathrm{E}$ as the SCS base point. Compo's et al.'s approach is adopted by a modification. (A brief description is given here, but further detail is provided in the first part of the supplemental material).

(i) The PHS type of cold surge:

The northeast Asian cold surge of the PHS type directs east-southeast from northeastern China into 


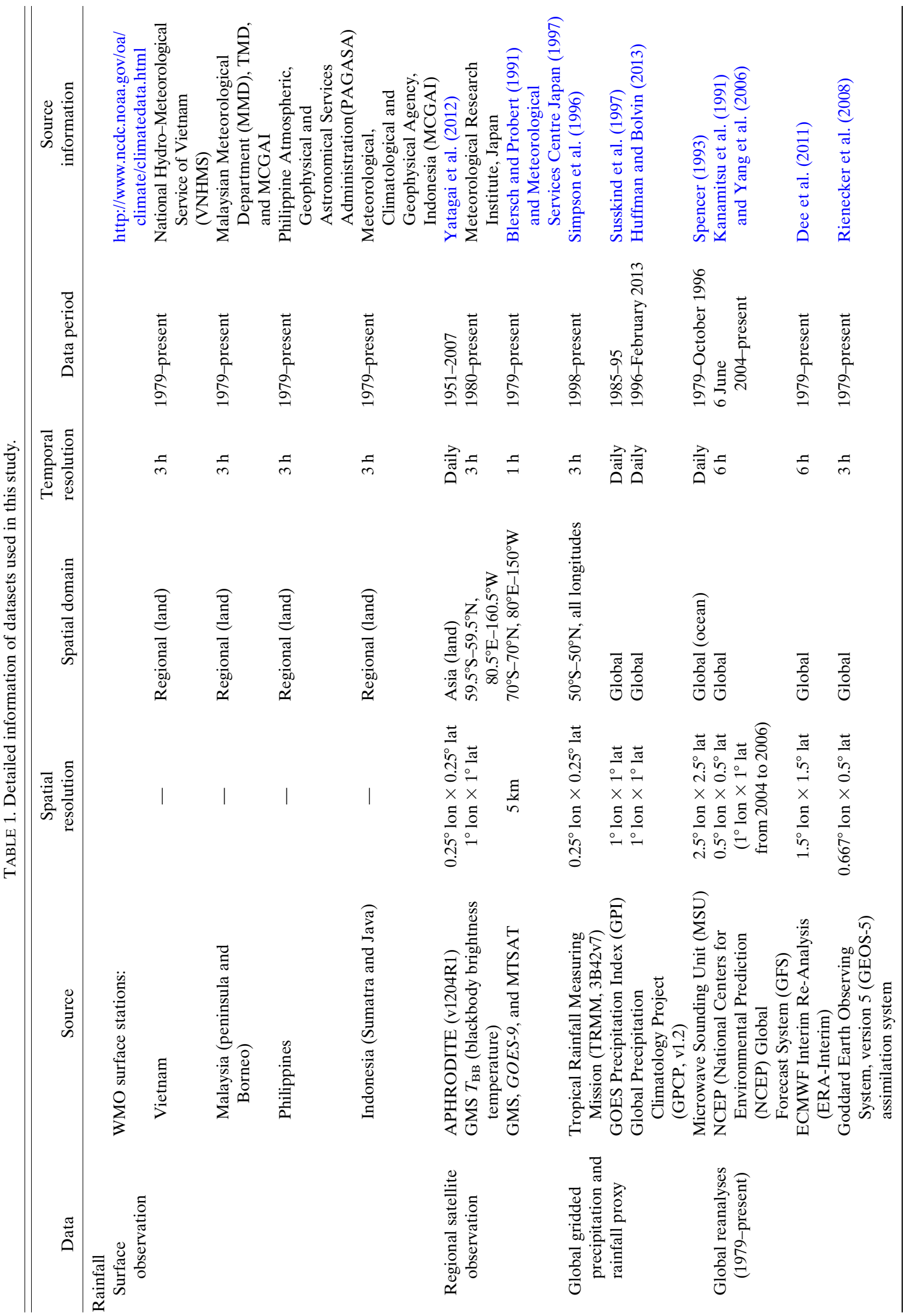




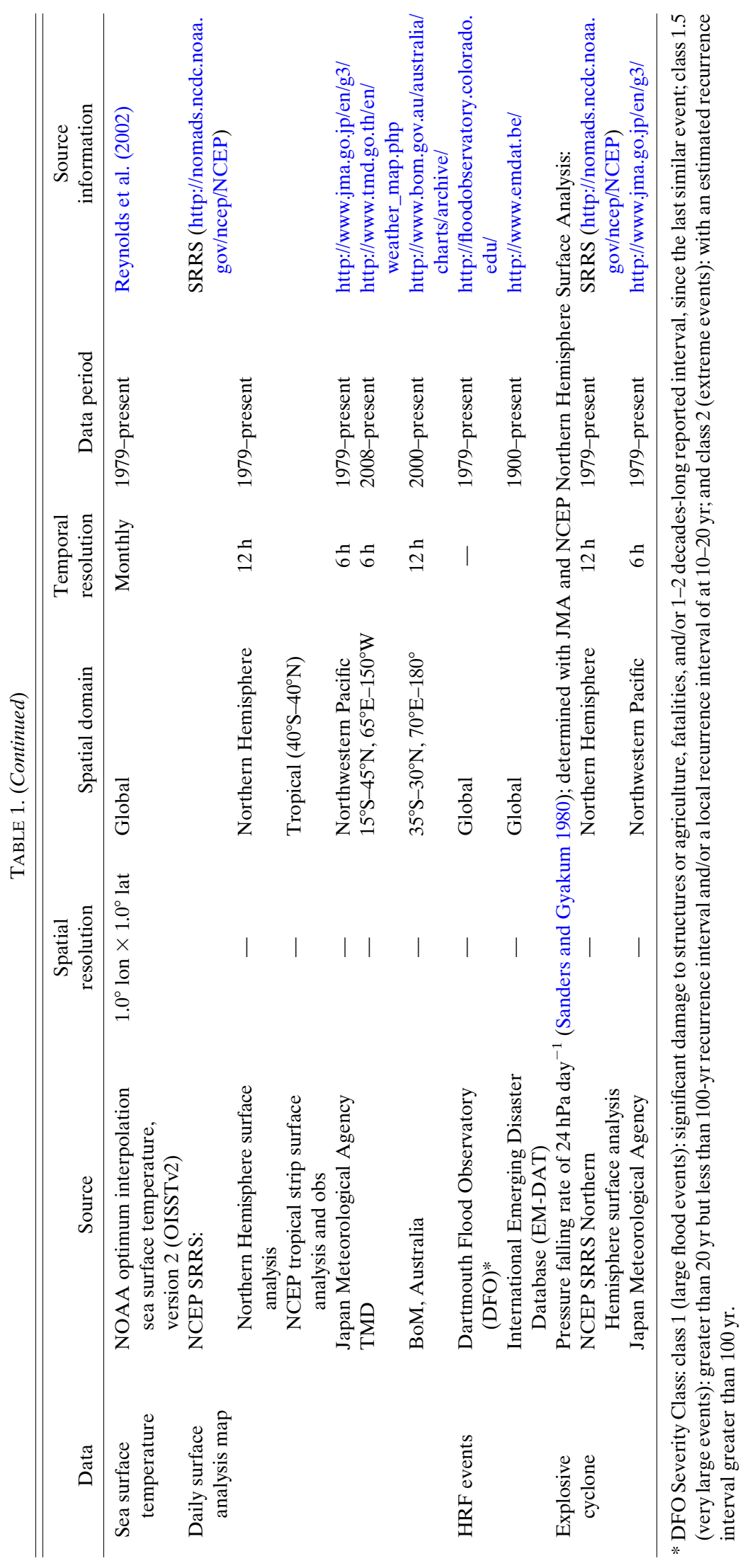


the open ocean, but the southern periphery of the high pressure cell exhibits its maximum northeasterly/easterly flow close to Compo et al.'s (1999) PHS base point in the Philippine Sea.

(ii) The SCS type of cold surge:

The northeast Asian cold surge of the SCS type directs south-southeast from northeastern Asia toward the East China Sea-western North Pacific region around the surface high pressure cell over China. The maximum isotach for this cold surge flow is close to Dongsha Island and Compo et al.'s (1999) SCS base point in the northern South China Sea.

- Issue 2: The flow type of cold surge related to either the westward propagating CSV(HRF) across or the stagnated CSV(HRF) by the demarcation line.

Because the meridional dimension of the South China Sea is over $2000 \mathrm{~km}$, a base point cannot fit all cold surge flows. The interaction of the cold surge flow with CSV(HRF) and the effect of cold surge flow on the CSV(HRF) propagation property across the South China Sea can occur at any latitudinal location. A more practical, but time-consuming, approach is to determine the flow pattern of every cold surge associated with the concerned CSV(HRF) by the following criteria (details are presented in the first part of the supplemental material).

(i) Stagnated/trapped CSV(HRF):

The CSV(HRF) becomes stagnant or trapped, when its $925-\mathrm{hPa}$ vorticity $[\zeta(925 \mathrm{hPa})]$ and vorticity tendency $\left[\zeta_{t}(925 \mathrm{hPa})\right]$ centers are coincident at a longitudinal location of the longitude-time diagrams of these two variables. Then, search is made to find the location of the maximum isotach within the South China Sea. The SCS-type cold surge flow inside the South China Sea is confirmed by the criterion where the meridional wind is less than the zonal wind at $925-\mathrm{hPa}[v(925 \mathrm{hPa})>u(925 \mathrm{hPa})]$ (see section 5). The mean longitudinal locations for the maximum isotach at latitudes from the northern to the southern South China Sea form the demarcation line of $\mathrm{CSV}(\mathrm{HRF})$ propagation. The identification of this SCS-type cold surge flow is also verified by the Compo et al.'s (1999) criterion in the South China Sea close to the SCS base point and the criterion in northeastern Asia.

(ii) Westward-propagating CSV(HRF):

When the CSV(HRF) center moves across the demarcation line, the flow, which meets the $u(925 \mathrm{hPa})>v(925 \mathrm{hPa})$ criterion at the location of maximum isotach in the South China Sea, is defined as the PHS-type cold surge flow. This identified PHS-type cold surge flow is validated by Compo et al.'s (1999) criterion in the South China
Sea close to the SCS base point and the criterion in northeast Asia.

\section{3) Shallow Surface Trough}

The formation mechanisms of the Philippine and Borneo CSV(HRF) are involved with the surface islandchain and the near-equator troughs, respectively. Daily 925-hPa streamline charts, supplemented with NCEP SRRS, JMA, and TMD surface analysis charts, can identify both troughs. An open trough in the low-level streamlines and surface pressure contours adjacent to the Philippines, Taiwan, and Okinawa island chain always reflects the island-chain trough. The near-equator trough is encircled by an east-west elongated cyclonic shear flow, extending eastward from the eastern tropical Indian Ocean, across the tropical South China Sea, to the tropical western Pacific. The formation of these two shallow surface troughs is facilitated by the existence of two climatological troughs. The climatology and spatial structure for these troughs will be presented in section 3 .

\section{Important elements of the cold-season Southeast Asia circulation}

During the cold season, the atmospheric circulation in the tropical western Pacific-South China Sea region is characterized by the winter monsoon; the cyclonic shear flow around the near-equator trough is overlaid by the upper-level anticyclone (Chen 2005). Thus, formation of the cold season weather disturbances over this region generally originates in the lower troposphere. Two preferred regions for the parent CSV(HRF) formation appear over the vicinity of the Philippines and Borneo (Fig. 2).

\section{a. Trough east of the East/Southeast Asia islands}

One of three necessary ingredients involved with the formation of the Philippine CSV(HRF) is the islandchain trough. This regional circulation element, which persistently appears in the formation of $\operatorname{CSV}(\mathrm{HRF})$, is a shallow surface trough (dashed purple line, Fig. 2) east of the western Pacific island chain. The Asian continental surface high encircled by the $925-\mathrm{hPa}$ streamfunction contours (Fig. 3a) is superimposed with the opposite sign of the vertical pressure velocity $(-\omega)$ at $925 \mathrm{hPa}$; three troughs emerge over the Indian Subcontinent, Indochina, and the ocean east of the North Pacific island chain. The two latter troughs are also well depicted by mean sea level pressure (Fig. 3c). Illustrated by the vertical distribution of $-\omega$ at $20^{\circ} \mathrm{N}$ on the latitudeheight cross sections of eddy streamfunction and geopotential height at $20^{\circ} \mathrm{N}$ (Figs. 3b), the island-chain 

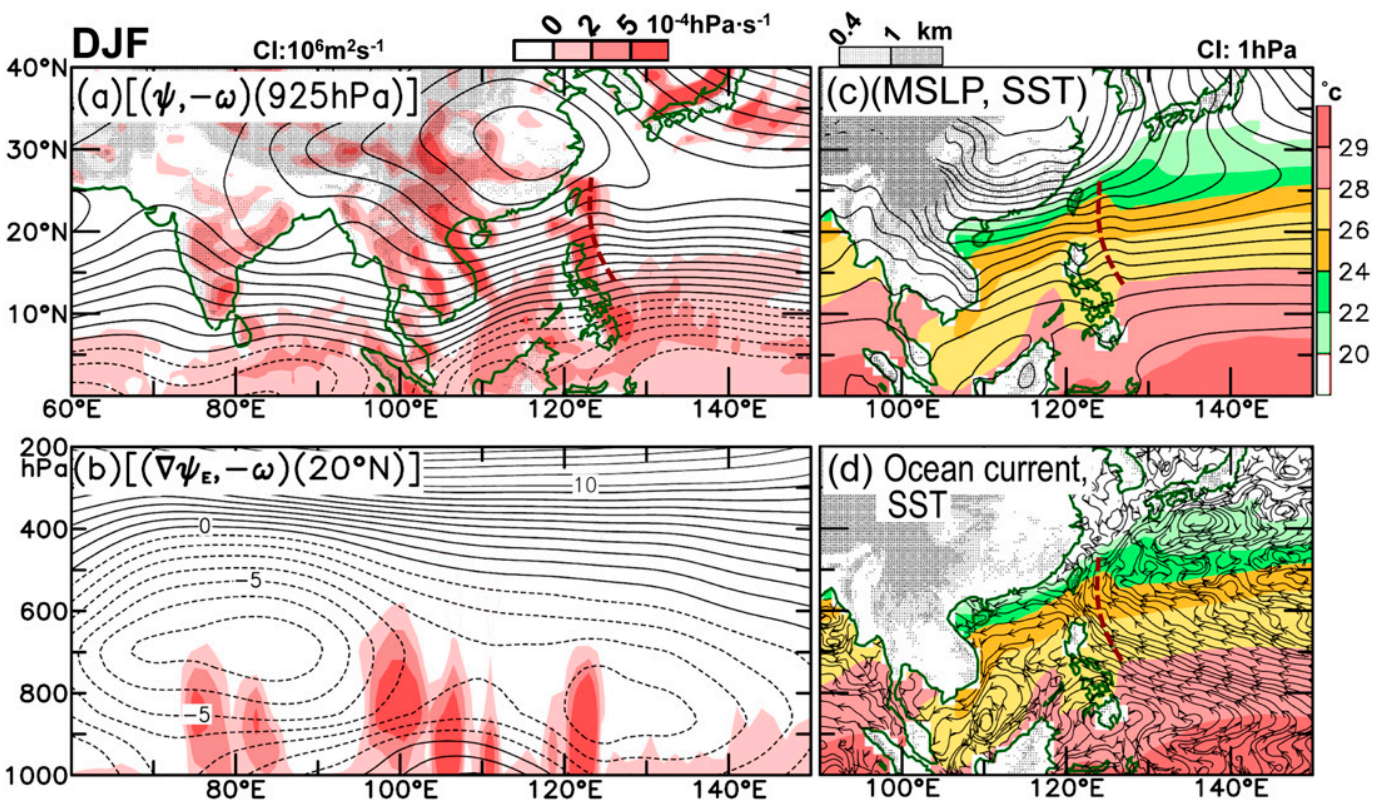

FIG. 3. (a) Winter climatology (DJF) of $925-\mathrm{hPa}$ streamfunction $(\psi)$ superimposed with $-\omega$ (red) (b) vertical cross section from (a) along $20^{\circ} \mathrm{N}$, (c) mean sea level pressure (MSLP; contours) superimposed with sea surface temperature (SST; displayed with color scale), and (d) mean ocean current superimposed with SST. The $\psi_{E}$ contour interval in (b) is divided into groups: $10^{6} \mathrm{~m}^{2} \mathrm{~s}^{-2}$ for $-12 \times 10^{6}<\psi_{E} \leq 12 \times 10^{6} \mathrm{~m}^{2} \mathrm{~s}^{-2}$ and $2 \times 10^{6} \mathrm{~m}^{2} \mathrm{~s}^{-2}$ for $\psi_{E}>12 \times$ $10^{6} \mathrm{~m}^{2} \mathrm{~s}^{-2}$. Elevation of orography is shaded by the grayscale at the top left of (c).

trough exists below $700 \mathrm{hPa}$. This trough is often reflected by an open dip south of Taiwan in the JMA surface analysis chart, but its dynamic role in the synoptic development of the East/Southeast Asia weather system is not well understood. The location of this trough line coincides with the Kuroshio (Fig. 3d), but the interaction of the trough and western boundary current has yet to be explained.

\section{b. Near-equator trough and cyclonic shear flow}

One of three basic ingredients included in the formation of Borneo CSV(HRF) is the near-equator trough. In Fig. 2, the near-equator trough (red dashed line) migrates equatorward across this island during the cold season. This trough was portrayed with the latitudeheight cross sections - streamfunction, vertical motion, and vorticity (see Figs. 11d-f of Chen et al. 2013a)where the trough extends vertically to the upper troposphere. The positive environmental vorticity and upward motion facilitate the formation of Borneo CSV(HRF). Additionally, the southward migration of this near-equator trough toward Java is a factor to the formation of Java HRF events, with or without Borneo CSVs involvement.

The near-equator trough is encircled by the eastwest elongated cyclonic shear flow, which will be shown later in the $925-\mathrm{hPa}$ streamline charts for all Borneo
CSV(HRF) formations. This shear flow may be intensified by the SCS-type cold surge flow around western Borneo. The intensification of this shear flow has two important implications. First, the deepening of the near-equator trough across Borneo by this shear flow intensification can facilitate the Borneo CSV(HRF) formation. Second, the westward advection of vorticity of CSV(HRF), which can be reduced by this shear flow intensification, hinders the westward propagation of Borneo CSV(HRF). In other words, the cyclonic shear flow of the near-equator trough plays an important role not only in the CSV(HRF) formation, but also in determining on which side of the South China Sea the HRF event may occur.

\section{Synoptic characteristics of the formation of CSV(HRF)}

Based on the locations and trajectories linked to formation locations of their parent CSV(HRF) (Fig. 2), the HRF events are divided into 10 groups in Table 2. These CSV(HRF) primarily form over the vicinity of the Philippines and Borneo, except four Java HRF events formed without parent CSV(HRF). The CSV(HRF) trajectories show HRF events west of the South China Sea may develop from both the Philippine and Borneo CSV(HRF). In contrast, HRF events east of the South 
TABLE 2. Formation preference of parent CSV(HRF) and their corresponding HRF cyclones/events. The preferred types of cold surge, time of day, and region for CSV(HRF) formation. The occurrence number of HRF cyclone/events and the time period covering these events are also included. All $181 \mathrm{HRF}$ cyclone/events identified by DFO over the seven cold-season rainfall centers in both sides of the SCS are developed from CSV(HRF), except three HRF events in Java (out of 23 during 1992-2012) are directly formed through the deepened/intensified the near-equator trough by the strong SCS type of cold surge flow, and one HRF event developed by a CSV(HRF) formed in the Celebes Sea.

\begin{tabular}{|c|c|c|}
\hline Region & $\begin{array}{l}\text { Parent CSV }(\mathrm{HRF}) \text { (preferred type of } \\
\text { cold surge, preferred formation time) }\end{array}$ & $\begin{array}{l}\text { HRF cyclone/event } \\
\text { (number, period) }\end{array}$ \\
\hline \multirow{5}{*}{$\begin{array}{l}\text { West of the SCS, developed from } \\
\text { westward propagating CSV(HRF) }\end{array}$} & Philippine (PHS type, 0600 UTC) & Central Vietnam $(37,1979-2012)$ \\
\hline & Philippine (PHS type, 0600 UTC) & Peninsular Malaysia $(18,1979-2012)$ \\
\hline & Philippine (PHS type, 0600 UTC) & Southeastern Sumatra $(4,1992-2012)$ \\
\hline & Borneo (SCS type, 0000 UTC) & Peninsular Malaysia $(17,1979-2012)$ \\
\hline & Borneo (SCS type, 0000 UTC) & Southeastern Sumatra $(7,1992-2012)$ \\
\hline \multirow{5}{*}{$\begin{array}{l}\text { East of the SCS, developed from } \\
\text { trapped CSV(HRF) }\end{array}$} & Philippine (PHS type, 0600 UTC)* & Northern Philippines $(18,1992-2012)$ \\
\hline & Philippine (PHS type, 0600 UTC)* & Southern Philippines $(23,1992-2012)$ \\
\hline & Borneo (in situ) (SCS type, 0000 UTC)* & Borneo $(38,1979-2012)$ \\
\hline & Borneo (in situ) (SCS type, 0000 UTC)* & Java $(19,1992-2012)$ \\
\hline & Java (in situ) (SCS type) & Java $(4,1992-2012)$ \\
\hline
\end{tabular}

* Four groups of CSV(HRF) are used to define the demarcation line of propagation for these CSV(HRF).

China Sea may develop either from the Philippine or in situ Borneo CSV(HRF). Thus, the development of HRF events from their parent CSV(HRF) may be reclassified into three groups: 1) westward-propagating CSV(HRF) from a distant region, 2) stagnated CSV(HRF) propagating from a nearby vicinity, and 3) trapped CSV(HRF). To avoid redundancy, the synoptic analysis for the formation of parent $\mathrm{CSV}(\mathrm{HRF})$ and their ensuing HRF cyclones/events over every rainfall center around the South China Sea is available online (http://eamex. iastate.edu/publication/synoptic_analysis_181HRF.pdf). The salient synoptic features, which emerge from the formations of different types of CSV(HRF), will be highlighted with individual typical examples.

\section{a. Westward-propagating $C S V(H R F)$ across the South China Sea}

\section{1) The Philippine CSV(HRF) DeVeloped Into A PENINSULAR MALAYSIA HRF CYCLONE/ EVENT}

As shown in Fig. 2, there are three groups of HRF cyclones/events ( 37 in central Vietnam, 18 in peninsular Malaysia, and 4 in southeastern Sumatra) that develop from the Philippine CSV(HRF). Although Chen et al. (2012a,c) analyzed central Vietnam HRF events, a typical peninsular Malaysia HRF event (9 November 2010) is selected in this study to examine whether salient features of the latter two groups behave as the central Vietnam cases (listed in the introduction). The rainfall rate for this peninsular Malaysia HRF event reaches $292 \mathrm{~mm} \mathrm{day}^{-1}$ at Kota Bharu (WMO identifier 48615). The salient synoptic features of this development are shown in Figs. 4a-c highlighted as follows: (i) The $925-\mathrm{hPa}$ streamline chart at 0600 UTC 4 November 2010 (Fig. 4a), verified by the JMA surface analysis chart, exhibits a surface islandchain trough (golden line) emerging east of the Philippines and Taiwan. A CSV(HRF) is formed in the southern Philippines through the interaction of an easterly wave (red line, Fig. 4a) with the northeast Asian cold surge flow and the islandchain trough.

(ii) Occurrences of the peninsular Malaysia HRF event and the northwestern Pacific explosive cyclone (marked in Fig. 4c) synchronize.

(iii) Maximum intensities (Fig. 14 of Part II) across the HRF cyclone/event, northeast Pacific explosive cyclone, and tropical trade easterlies take place simultaneously when this HRF event occurs.

(iv) The basic characteristics (size, speed, and rainfall) of this Philippine CSV(HRF) are smaller than the corresponding HRF cyclone/event.

These synoptic features are common to formation of the CSV(HRF), which develops into the peninsular Malaysia and Sumatra HRF cyclones/events, as are all identified central Vietnam HRF cyclones/events.

Additional synoptic features identified in the formation of the Philippine CSV(HRF) linked to the three rainfall centers west of the South China Sea are the following:

(i) The island-chain surface trough is an indispensable synoptic element to the formation of the Philippine CSV(HRF).

(ii) The preferred formation time of the Philippine CSV(HRF) is 0600 UTC (1400 LST; Fig. 4b). The 


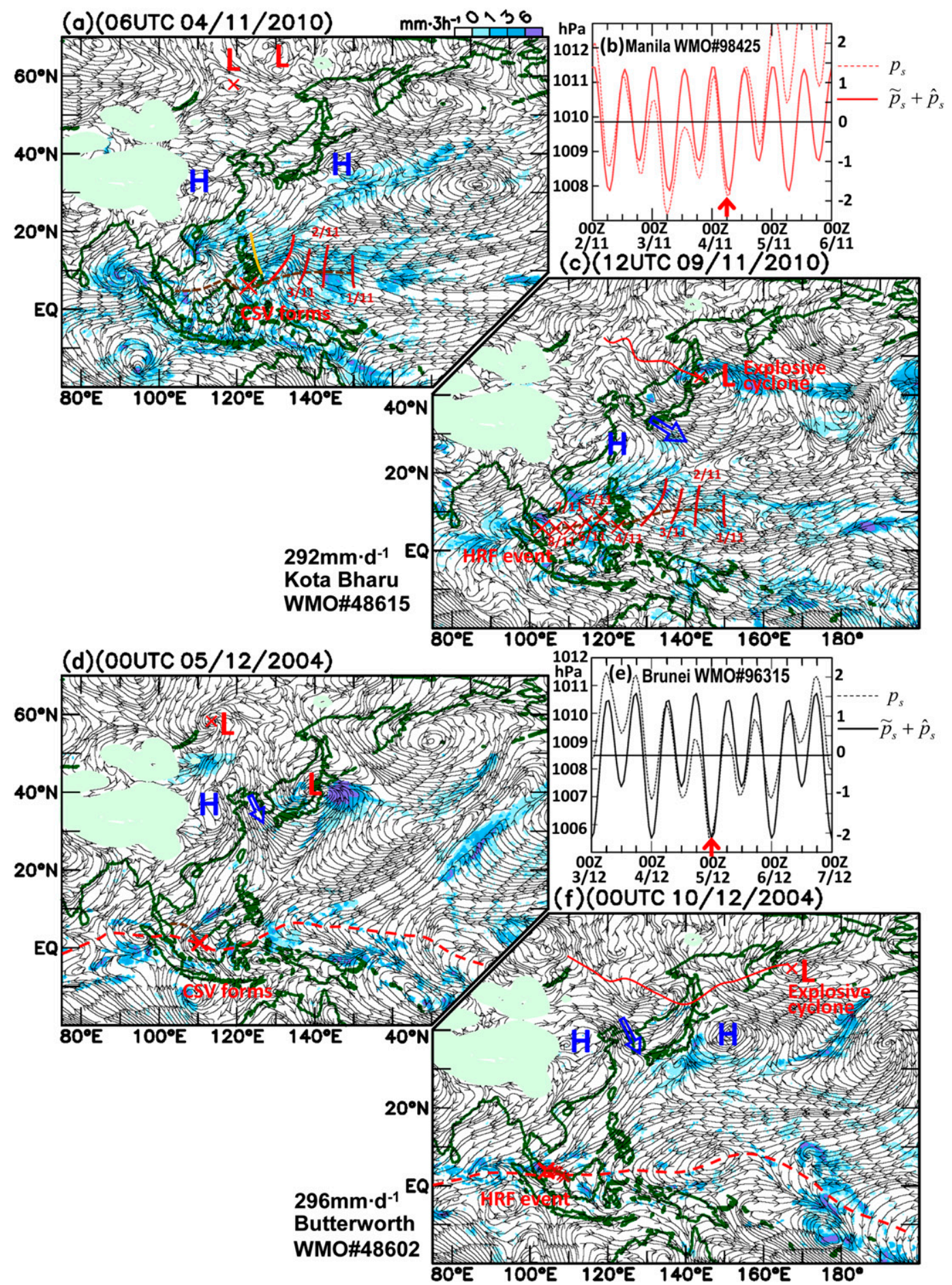

FIG. 4. (a) The 925-hPa streamline chart superimposed with TRMM precipitation at 0600 UTC 4 Nov 2010 for CSV(HRF) formed in the Philippine Sea. (b) Surface pressure $\left(p_{s}\right.$, dashed red line) and its diurnal $\left(\tilde{p}_{s}\right)$ and semidiurnal $\left(\hat{p}_{s}\right)$ components (solid red line) combined at Manila (WMO identifier 98425) added with the CSV(HRF) formation time (red arrow). (c) The Philippine CSV(HRF) in (a) propagated westward and developed into a HRF event in peninsular Malaysia at 1200 UTC 9 Nov 2010. (d)-(f) As in (a)-(c), except showing (d) the CSV(HRF) formation time at 0000 UTC 5 Dec 2004 in Borneo that then (f) propagated westward and developed into a peninsular Malaysia HRF event at 0000 UTC 10 Dec 2004. (e) Time series of $p_{s}$ (dashed black line) and $\tilde{p}_{s}+\hat{p}_{s}$ (solid black line) at Brunei Airport (WMO identifier 96315), Borneo. 


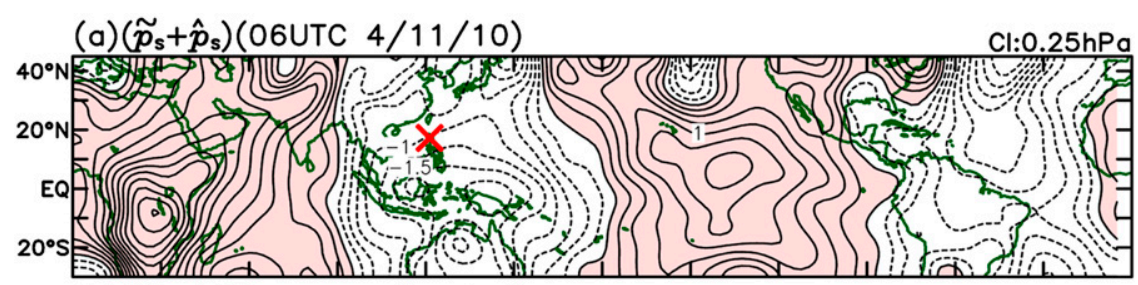

(b) $\left(\tilde{p}_{\mathrm{s}}+\hat{p}_{\mathrm{s}}\right)$ (OOUTC $\left.5 / 12 / 04\right)$

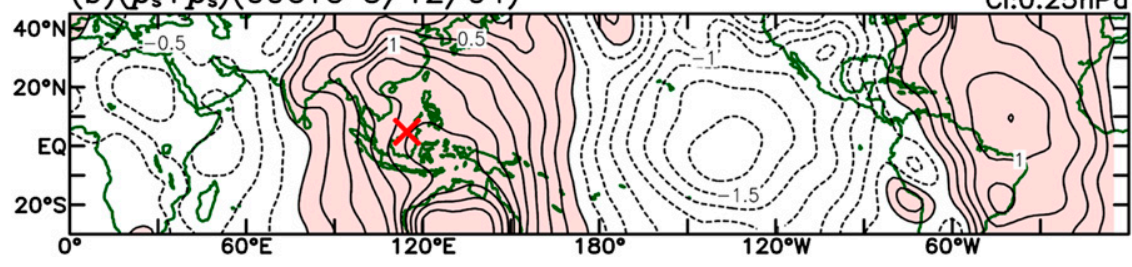

FIG. 5. Global distributions for $\tilde{p}_{s}+\hat{p}_{s}$ at (a) 0600 UTC 4 Nov 2010 (Philippine to Malaysia case) and (b) 0000 UTC 5 Dec 2004 (Borneo to Malaysia case) correspond to Figs. 4b and 4e, respectively.

minimum value of the semidiurnal surface pressure component propagates across the Maritime Continent [Fig. 5a, predicted by Lindzen (1971)].

The differences in the synoptic features of the formation and development of the three CSV(HRF) groups are the following:

(i) Trajectories of the Philippine CSV(HRF) to peninsular Malaysia and southeastern Sumatra are longer than those to central Vietnam, and so are the traveling times ( 7.5 days for the former two groups, and 4.5 days for the latter group).

(ii) The seasonal march of the Southeast Asia monsoon circulation leads to the southward migrations of the Philippine CSV(HRF) formation, and the northeasterlies north of the near-Equator trough.

\section{2) BORNEO CSV(HRF) DEVELOPED INTO PENINSULAR MALAYSIA HRF CYCLONE/ EVENT}

From Table 2, half (17) of peninsular Malaysia and seven southeastern Sumatra HRF cyclones/events developed from Borneo CSV(HRF). The synoptic features for development of a typical Borneo CSV(HRF) into a peninsular Malaysia HRF cyclone/event are shown in the lower panels of Figs. 4d-f:

(i) During the deep winter, the near-equator trough migrates farther south across Borneo (Fig. 2). The strong SCS-type cold surge flow intensifies the cyclonic shear flow around Borneo and deepens this near-equator trough. The interaction among these synoptic elements facilitates the Borneo
CSV(HRF) formation at 0000 UTC 5 December 2008 (Fig. 4d).

(ii) Five days later, the SCS-type cold surge flow yields to a new PHS-type cold surge flow (Fig. 4f). The easterlies of this cold surge flow allow this Borneo $\mathrm{CSV}(\mathrm{HRF})$ to propagate westward to peninsular Malaysia and form a HRF cyclone/event on the near-equator trough. This HRF event produced a rainfall rate of $296 \mathrm{~mm}$ day $^{-1}$ measured at the Butterworth (WMO identifier 48602).

(iii) Occurrences of the peninsular Malaysia HRF cyclone/event and the northwestern Pacific explosive cyclone (Fig. 4f) are synchronized and accompanied with the simultaneous occurrences of the maximum easterlies of the peninsular Malaysia HRF and westerlies of the northwestern Pacific explosive cyclone and tropical trade easterlies (Fig. 14 of Part II).

(iv) The basic characteristics for this CSV(HRF) and its corresponding HRF cyclone/event behave the same way as that for the Philippine CSV(HRF) and its HRF cyclone/event.

These synoptic features are typical to both the peninsular Malaysia and southeastern Sumatra HRF cyclones/events developed from Borneo CSV(HRF), and the three groups of HRF cyclone/events developed from the Philippine CSV(HRF).

Some significant differences of synoptic features exist between HRF cyclones/events developed from the Philippine and Borneo CSV(HRF):

(i) The near-equator trough in the Borneo CSV(HRF) formation replaces the island-chain trough in the Philippine CSV(HRF) formation, except the latter formation is not involved with an easterly wave. 


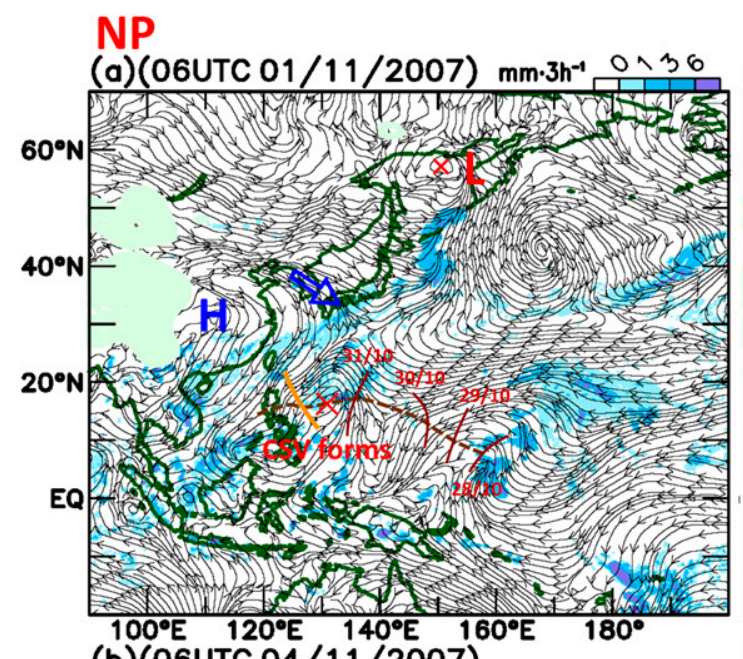

SP

(c) $(06$ UTC 09/02/2012)

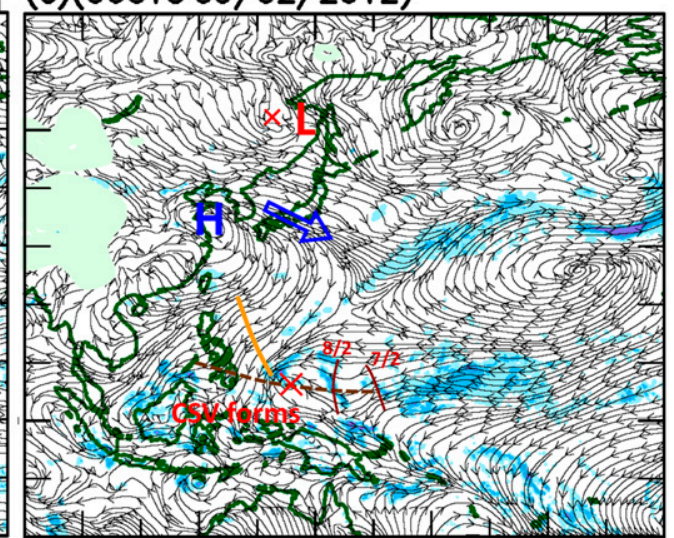

(b) (06UTC 04/11/2007)

$100^{\circ} \mathrm{E} \quad 120^{\circ} \mathrm{E} \quad 140^{\circ} \mathrm{E} \quad 160^{\circ} \mathrm{E} \quad 180^{\circ}$

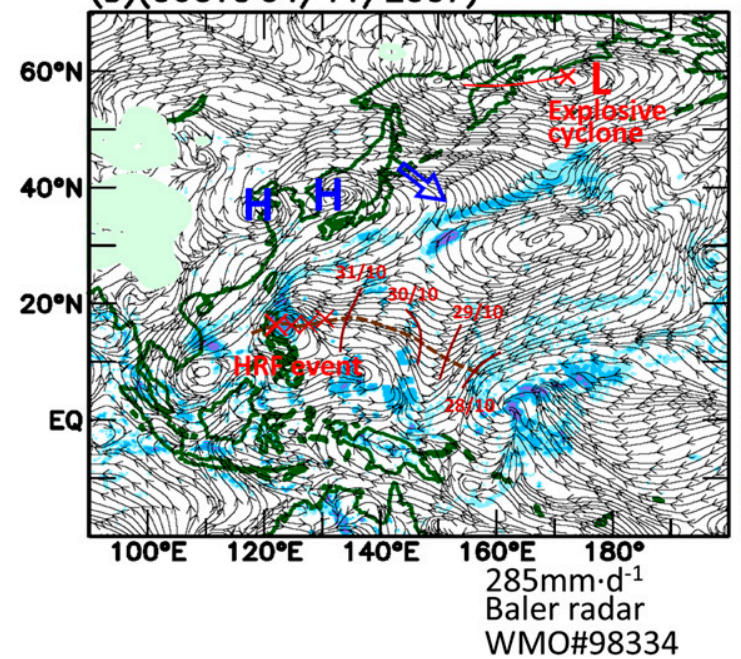

(d) $(12$ UTC 11/02/2012)

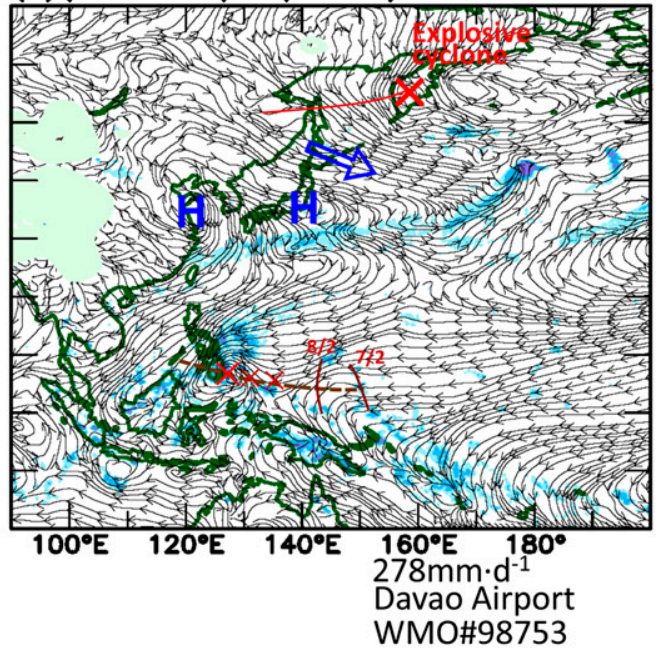

FIG. 6. The 925-hPa streamline chart superimposed with TRMM precipitation (a) at 0600 UTC 1 Nov 2007 of CSV(HRF) formed in the Philippine Sea, then propagated westward and (b) developed into a Luzon HRF event at 0600 UTC 4 Nov 2007. (c),(d) As in (a),(b), but for the CSV(HRF) formed at 0600 UTC 9 Feb 2012 in the Philippine Sea and a Mindanao HRF event at 1200 UTC 11 Feb 2012.

(ii) The formation time of day for the majority $(78 \%)$ of Borneo CSV(HRF) is 0000 UTC (Fig. 4e), when surface pressure $\left(p_{s}\right)$ and the sum of the diurnal and semidiurnal components $\left(\tilde{p}_{s}+\hat{p}_{s}\right)$ exhibit their minimum values. Figure $5 \mathrm{~b}$ shows the maximum value of $\tilde{p}_{s}+\hat{p}_{s}$ (essentially contributed by $\hat{p}$ ) appearing over the Maritime Continent (Fig. 5b). According to Houze et al. (1981), this 6-h phase difference is likely caused by the morning convection stimulated by the collision of the cold morning downslope flow in western Borneo with the strong northerlies of the SCS-type cold surge flow.

(iii) The westward propagation of the Borneo CSV(HRF) to peninsular Malaysia is attributed to the transition of the strong SCS-type cold surge flow [five days after the Borneo CSV(HRF) formed] to a PHS-type cold surge flow.

\section{b. Philippine CSV $(H R F)$ stagnated at the east side of the South China Sea}

\section{1) The NORThern PhiLipPINes}

Most of the northern Philippine HRF events, which occur north of $10^{\circ} \mathrm{N}$ (Fig. 2d), develop from Philippine CSV(HRF) in the central Philippine Sea. Major synoptic features related to the formation of central Vietnam HRF events and their parent CSV(HRF) also appear in the northern Philippine HRF events. However, some unique synoptic features of the northern Philippine HRF case include the following:

(i) The Philippine CSV(HRF) (Fig. 6a) is formed by the interaction of an easterly wave with the surface 
island-chain trough and a PHS-type cold surge at 0600 UTC 1 November 2007.

(ii) The traveling time ( $\sim 3$ days) for this Philippine CSV(HRF) to form a Philippine HRF event is shorter than the time for the central Vietnam HRF events to form. This event produced a rainfall rate of $285 \mathrm{~mm} \mathrm{day}^{-1}$ at the Baler radar (WMO identifier 98334).

(iii) The northeast Asian surface low [coupled with the cold surge flow, which forms the Philippine CSV(HRF)] develops into a northwestern Pacific explosive cyclone. Occurrence of this cyclone synchronizes with the northern Philippine HRF event.

(iv) The short traveling time of the parent Philippine $\mathrm{CSV}(\mathrm{HRF})$ is caused by the fact the corresponding HRF cyclone/event is prevented from propagating westward by the strong northerlies of a SCS-type cold surge flow (Fig. 6b).

\section{2) The SOUTHERn PHILIPPINES}

The majority of the southern Philippine HRF events, which occur south of $10^{\circ} \mathrm{N}$, develop from the Philippine CSV(HRF) south of $10^{\circ} \mathrm{N}$ (Fig. 2d). These CSV(HRF) are formed by the same mechanism at 0600 UTC as the northern Philippine CSV(HRF) (Fig. 6a). Synoptic features related to formations of $\operatorname{CSV}(\mathrm{HRF})$ and the HRF event in the southern Philippines include the following:

(i) Being formed close to the near-equator trough (Fig. 6c), this southern Philippine CSV(HRF) eventually merges with this trough (Fig. 6d) to form the southern Philippine HRF event and produce a rainfall rate of $278 \mathrm{~mm} \mathrm{day}^{-1}$ at the Davao Airport (WMO identifier 98753).

(ii) It takes only two days for this southern CSV(HRF) to propagate from the southern Philippine Sea to Mindanao and form a HRF event, which synchronizes with the occurrence of a northwestern Pacific explosive cyclone (Fig. 6d).

(iii) This southern Philippine HRF cyclone/event is embedded in the near-equator trough and prevented from propagating westward by the strong northerlies of a SCS-type cold surge flow (Fig. 6d).

\section{c. Tropical Borneo CSV(HRF) on the east side of the South China Sea}

During the deep winter, the near-equator trough migrates across Borneo to the equator and facilitates the Borneo CSV(HRF) formation, when the SCS-type cold surge flow appears near western Borneo. Shown in Table 2, 38 Borneo and 19 Java HRF events develop from Borneo CSV(HRF). Additionally, three Java HRF events develop from the direct interaction of the SCStype cold surge flow with the near-equator trough, and another one develops from the Celebes Sea CSV(HRF). Despite the difference in the origin of their parent CSV(HRF), developments of Borneo and Java HRF cyclones/events exhibit the same basic synoptic features of the HRF cyclones/events west of the South China Sea and the Philippine HRF cyclones/events. Therefore, we only highlight those special features, which differ from those for the HRF cyclones/events west of the South China Sea and the Philippines.

\section{1) TRAPPED Borneo CSV(HRF) DEVELOPED INTO BORNEO HRF EVENT}

(i) A Borneo CSV(HRF) is formed at 0000 UTC 18 December 2011 through the deepening of the nearequator trough by a SCS-type cold surge flow around western Borneo. The basic elements required for this CSV(HRF) formation are the nearequator trough, the SCS-type cold surge flow, and Borneo orography (Fig. 7a).

(ii) The formation time for this Borneo $\mathrm{CSV}(\mathrm{HRF})$ is 0000 UTC (which is different from the Philippines, at 0600 UTC). Houze et al. (1981) argue that minimum surface pressure appears when the cold morning downslope flow collides with strong easterlies from a SCS-type cold surge flow.

(iii) The 25 December 2011 Borneo HRF cyclone/ event, developed from the trapped CSV(HRF) (Fig. 7b), produced a rainfall rate of $282 \mathrm{~mm} \mathrm{day}^{-1}$ at Sibu (WMO identifier 96421).

\section{2) TRAPPED Borneo CSV(HRF) DEVELOPED INTO A JAVA HRF CYCLONE/EVENT}

Developments of Java HRF events are classified into two groups-with and without Borneo CSV(HRF). The synoptic condition of a typical case for each group is shown in Fig. 7.

\section{(i) Java HRF cyclonelevent developed with a Borneo CSV $(H R F)$}

The synoptic condition for the parent Borneo CSV(HRF) formation (at 0000 UTC 15 January 2007) of the Java HRF event (23 January 2007) (Fig. 7c) resembles that for the Borneo HRF event (Fig. 7a)-the interaction among the SCS-type cold surge flow, the nearequator trough, and Borneo orography are presented. To save space, the synoptic development of this Java $\mathrm{HRF}$ cyclone/event is posted online (http://eamex.iastate. edu/publication/synoptic_10HRF.pdf). This Java HRF cyclone/event centered on western Borneo produced a rainfall rate of $340 \mathrm{~mm} \mathrm{day}^{-1}$ at the Tanjung Priok 

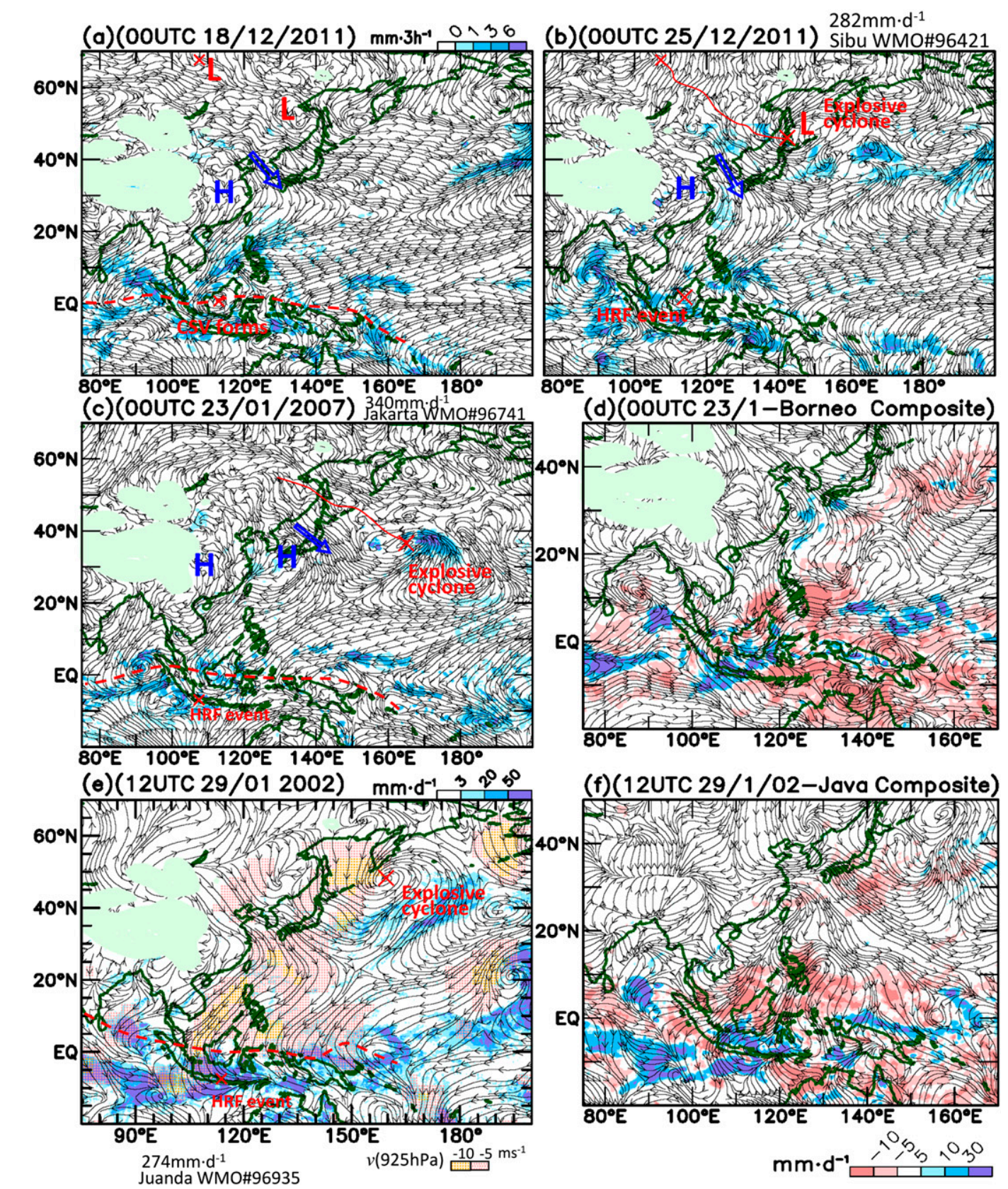

FIG. 7. The $925-\mathrm{hPa}$ streamline superimposed with TRMM precipitation for (a) a CSV(HRF) formed at 0000 UTC 18 Dec 2011 in Borneo and (b) developed into a Borneo HRF event Borneo at 0000 UTC 25 Dec 2011. (c) A Java HRF event formed by Borneo CSV(HRF) and (d) the circulation departure between (c) and the composite of all Borneo HRF events. (e),(f) As in (c),(d), but for the Java HRF events developed without a Borneo CSV(HRF).

subdistrict of Jakarta (WMO identifier 96741). Although the rainfall center for this HRF event appears only across the narrow Java Sea, some major difference is expected between the synoptic conditions of the Java and Borneo HRF event. This difference is illustrated by the departure of the $925-\mathrm{hPa}$ wind vector and precipitation $\{\Delta[\mathbf{V}(925 \mathrm{hPa}), P]$; Fig. $7 \mathrm{~d}\}$, the difference between $[\mathbf{V}(925 \mathrm{hPa}), P]$ for this Java HRF event (Fig. 7c), and the composite $[\mathbf{V}(925 \mathrm{hPa}), P]$ for all Borneo HRF events. An anomalous cyclonic circulation around the Java HRF rainfall center emerges. The convergence of water vapor flux is enhanced to maintain 
the Java HRF rainfall center by the southward migration of the near-equator trough.

\section{(ii) Java HRF cyclone/event developed without} a Borneo CSV $(H R F)$

Three Java HRF events develop from the direct interaction of the SCS-type cold surge flow with the nearequator trough without the presence of a Borneo CSV(HRF). The synoptic conditions of a Java HRF event (29 January 2002) are shown in Fig. 7e. The nearequator trough is deepened by the strengthening of the cyclonic shear flow around western Borneo by a wellorganized SCS-type cold surge flow, and enables this cyclonic flow to move across Java and reach Christmas Island. This synoptic development can be perceived through the anomalous cyclonic flow pattern around Java depicted by $\Delta[\mathbf{V}(925 \mathrm{hPa}), P]$ on 29 January 2002 (Fig. 7f), the difference between $[\mathbf{V}(925 \mathrm{hPa}), P]$ on 29 January 2002, and composite [ $\mathbf{V}(925 \mathrm{hPa}), P]$ of 19 Java HRF events. This synoptic change leads to the formation of this Java HRF event.

\section{d. Summary}

Most salient synoptic features identified for the development of CSV(HRF) into central Vietnam HRF events are common to individual typical cases of the 10 groups of CSV(HRF) presented in Table 2. Additional to these features, other newly identified features are classified into three components, listed here.

\section{1) Formation MECHANISM OF CSV(HRF)}

- The Philippine CSV(HRF) are formed by the interactions of an easterly wave with the PHS-type cold surge flow and the surface island-chain trough.

- The Borneo CSV(HRF) are formed by the interactions among the SCS-type cold surge flow, the nearequator trough, and Borneo orography.

- The preferred formation time of the Philippine CSV(HRF) is 0600 UTC, coincident with the local time of the minimum semidiurnal surface pressure. For a Borneo CSV(HRF), the preferred formation time is 0000 UTC, which matches well with the morning convection by the interaction of the cold morning downslope flow with the SCS-type cold surge flow.

\section{2) Propagation properties of CSV(HRF)}

- Two types (PHS and SCS) of cold surge flows determine the propagation properties of CSV(HRF) across the South China Sea. The Philippine (Borneo) CSV(HRF) propagate (stagnate) westward (in situ) to the west (east) of the South China Sea when the PHS (SCS)-type cold surge flow exists across this sea.
- The near-equator trough exhibits an equatorward migration from late fall to deep winter. The intensification of the cyclonic shear flow around this trough hinders the westward propagation of the Philippine and Borneo CSV(HRF) across the South China Sea.

\section{3) FORMATION OF HRF CYCLONES/EVENTS}

- The formation locations of HRF cyclones/events are determined by the propagation properties of their parent CSV(HRF).

- The intensity (deepening) of the near-equator trough south of the equator facilitates the formation of Java HRF events.

The next two sections are devoted to explore whether these newly identified synoptic features for the formation of individual typical CSV(HRF) in this section are common to the corresponding groups of $\mathrm{CSV}(\mathrm{HRF})$.

\section{Formation mechanisms of $\mathrm{CSV}(\mathrm{HRF})$}

\section{a. Preferred mechanism and geographic location}

The formation mechanisms of the Philippine and Borneo CSV(HRF) were synoptically identified in section 4. One may question whether these two formation mechanisms work for all identified CSV(HRF) in their corresponding group shown in Figs. 2a-e.

The following definitions for easterly waves, the island-chain trough, and the PHS-type cold surge flow presented in section 2, 100 Philippine CSV(HRF) (related to $59 \mathrm{HRF}$ events west of the South China Sea, and another $41 \mathrm{HRF}$ events east of this sea) are verified/ validated against all necessary and available charts to determine if the formation mechanism of the Philippine CSV(HRF) works for all of them. As confirmed in Table 3, all of these $\mathrm{CSV}(\mathrm{HRF})$ are generated by the same mechanism.

Borneo CSV(HRF) lead to the formation of HRF events, which occur not only in Borneo (38 in situ) and Java (19) during December-February, but also over peninsular Malaysia (17) and Sumatra (7) during NovemberDecember. Regardless of the postformation development of Borneo CSV(HRF) into HRF events in remote or in situ regions, one may question whether all 81 Borneo CSV(HRF) are formed by the same mechanism. This question is also clarified in Table 4, except for four Java HRF events develop without Borneo CSV(HRF).

Formation locations for both Philippine and Borneo CSV(HRF) exhibit their geographic preference in Fig. 2. To facilitate confirmation of the finding, formation locations for these two groups of CSV(HRF) against the December-February 925 -hPa streamline charts are shown in Fig. 8. Tables 3 and 4 reveal the 
newly identified synoptic element needed for the formation of Philippine CSV(HRF) is the island-chain trough adjacent to the Philippines and for Borneo $\mathrm{CSV}(\mathrm{HRF})$ this required element is the near-equator trough across Borneo. As presented in section 3, the climatological location of the island-chain trough exists east of the Philippines from late fall to early winter and the climatological location of the near-equator trough appears longitudinally across Borneo during winter. The climatological locations for these two troughs are conducive to the synoptic developments of these two troughs in the vicinity of the Philippines and Borneo, respectively, and result in the geographic preference for the formation of these two CSV(HRF) groups.

\section{b. Preferred time and cold surge flow type}

As observed in section 4,1) the preferred formation time of the Philippine CSV(HRF) is 0600 UTC under the influence of the PHS-type cold surge flow, and 2) the Borneo CSV(HRF) forms at 0000 UTC with the impact of the SCS-type cold surge flow. Can all 181 CSV(HRF) formations over these two regions have a clear distinction in the preferred time and type of cold surge flow? The maximum vorticity of CSV(HRF) is used as an indicator of this vortex strength whose magnitude is projected on the radius of a 24-h clock for the Philippine (Fig. 9a) and Borneo (Fig. 9b) CSV(HRF). Three basic characteristics [magnitude of maximum vorticity $\zeta(850 \mathrm{hPa})$, formation time, and the cold surge flow type involved with the CSV(HRF) formation] for every identified CSV(HRF) are projected on Figs. 9a and 9b. Another 261 Philippine nondeveloped (NOD) CSV [CSV(NOD)] and 266 Borneo CSV(NOD) are also projected on these two clocks for comparison with CSV(HRF).

The salient features that emerge from Figs. 9a and 9b are explained below.

1) A great majority (78\%) of the Philippine CSV(HRF) form at 0600 UTC, under the PHS type of cold surge flow, but $11 \%$ form at 0300 UTC and another $11 \%$ form at 0900 UTC. The preferred CSV(HRF) formation time for this group is during the local afternoon. The Philippine CSV(NOD) do not show any preferred formation time of day. The maximum $\zeta(850 \mathrm{hPa})$ magnitudes for CSV(NOD) are significantly smaller than CSV(HRF).

2) The majority (59\%) of the Borneo CSV(HRS) form at 0000 UTC, while $41 \%$ form at 2100 UTC. Both preferred CSV(HRF) formation times for this group are during the local morning. The Borneo CSV(NOD) formation shows no preferred time of day. The maximum $\zeta(850 \mathrm{hPa})$ magnitudes of $\mathrm{CSV}(\mathrm{NOD})$ are also smaller than CSV(HRF). 
TABLE 4. As in Table 3, but for Borneo CSV(HRF).

\begin{tabular}{|c|c|c|c|c|}
\hline Season & November-December & December-January & December-February & January-February \\
\hline $\begin{array}{l}\text { Rainfall center } \\
\text { (No. of HRF events) }\end{array}$ & $\begin{array}{r}\text { Peninsular Malaysia } \\
\text { (17 from Borneo) }\end{array}$ & $\begin{array}{l}\text { Sumatra (7 from } \\
\text { Borneo) }\end{array}$ & Borneo (38 in situ) & Java (19 from Borneo) \\
\hline Near-equator trough $(T)$ & All 17 events $T$ & All 7 events $T$ & All 38 events $T$ & $\begin{array}{l}19 \text { events } T \text { and } 4 \text { events } T \\
\text { without Borneo CSV(HRF) }\end{array}$ \\
\hline Orography $(\mathrm{O})$ & All 17 events $\mathrm{O}$ & All 7 events $\mathrm{O}$ & All 38 events $\mathrm{O}$ & $\begin{array}{l}19 \text { events } \mathrm{O} \text { and } 4 \text { events } \mathrm{O} \\
\text { without Borneo CSV(HRF) }\end{array}$ \\
\hline Cold surge SCS-type (S) & All 17 events S & All 7 events $S$ & All 38 events $S$ & $\begin{array}{l}19 \text { events S and } 4 \text { events } S \\
\text { without Borneo CSV(HRF) }\end{array}$ \\
\hline $\begin{array}{l}\text { Propagation property of } \\
\text { parent CSV(HRF) }\end{array}$ & Westward & Westward & Stagnated & Stagnated \\
\hline
\end{tabular}

The preferred time and cold surge flow type of CSV(HRF) formation shown in Figs. 9a-c have the following implications:

1) The preferred formation time for the Philippine CSV(HRF) at 0600 UTC (Fig. 9a), local afternoon, is attributed to two factors: (i) The sea surface temperature (Fig. 3c) over the western tropical Pacific is warmer than the remaining tropical Pacific. The daily shortwave heating facilitates the afternoon convection (e.g., Nitta and Sekine 1994). (ii) The surface pressure in the vicinity of the Philippines is primarily deepened by the semidiurnal component (Fig. 4b) to reach a minimum at 0600 UTC (Fig. 5a) and trigger the CSV(HRF) formation. This argument is supported by the minimum $\Delta p_{s}$ at the Philippine surface stations close to CSV(HRF) centers (Fig. 9c).

2) The preferred formation time for Borneo CSV(HRF) is during the morning (2100-0000 UTC) (Fig. 9b), which is about $6-7 \mathrm{~h}$ ahead of the Philippine CSV(HRF) formation time, approximately a halfcycle of semidiurnal surface pressure. The surface pressure over Borneo at 0000 UTC reaches its maximum primarily due to the semidiurnal $p_{s}$ component (Fig. 9c). The preferred formation time of a Borneo CSV(HRF) may be well attributed to the Houze et al. (1981) mechanism explained previously.

\section{Propagation properties of $\mathrm{CSV}(\mathrm{HRF})$}

Analyzing the rain-producing weather systems related to the winter rainfall in Malaysia, Chen et al. (2013a) found the propagation properties for Borneo CSV(HRF) are regulated by the cold surge flow pattern in the South China Sea. The PHS-type cold surge flow with strong well-organized easterlies makes the westward propagation of these CSV(HRF) and HRF cyclones/events possible. In contrast, the stagnation of these disturbances is caused by the SCS-type cold surge flow with strong northerlies. All HRF events in the rainfall centers west of the South China Sea, and over both the northern and southern Philippines develop from the Philippine $\mathrm{CSV}(\mathrm{HRF})$. Can the two types of cold surge flows regulate the propagation properties for these CSV(HRF)?

The vertical structure for the winter circulation in the western tropical Pacific is illustrated by the latitudeheight cross section of the eddy streamfunction and vorticity $\left(\psi_{E}, \zeta\right)$ at $124^{\circ} \mathrm{E}$ during October-November in Fig. 10a, including a location mark for the island-chain trough. The monsoon circulation structure is characterized by a vertical phase change in the midtroposphere. The vertical extent of a CSV(HRF) is limited by the upper-level anticyclone, as illustrated for the case of 14 October 2008 shown in Fig. 10b. Thus, the CSV(HRF) is primarily steered westward by the low-tropospheric flow.

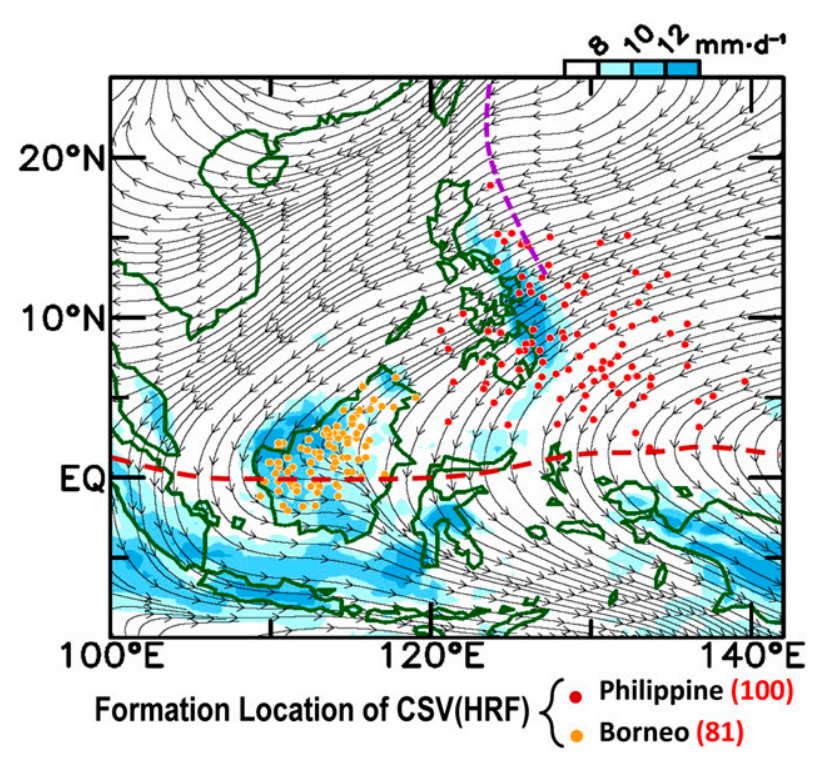

FIG. 8. Formation location for October-February of the Philippine CSV(HRF) (red dots) against the island-chain trough (purple dashed line) and Borneo CSV(HRF) (gold dots) against the nearequator trough (red dashed line) superimposed on the DecemberFebruary 925-hPa streamline chart. 
(a)PHS CSV(HRF) $00 Z$

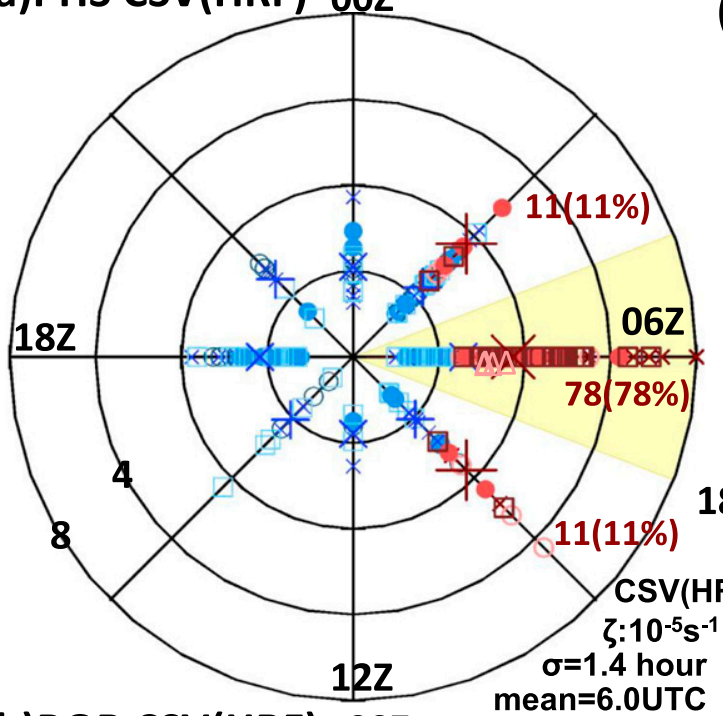

(b)BOR CSV(HRF) $00 Z$

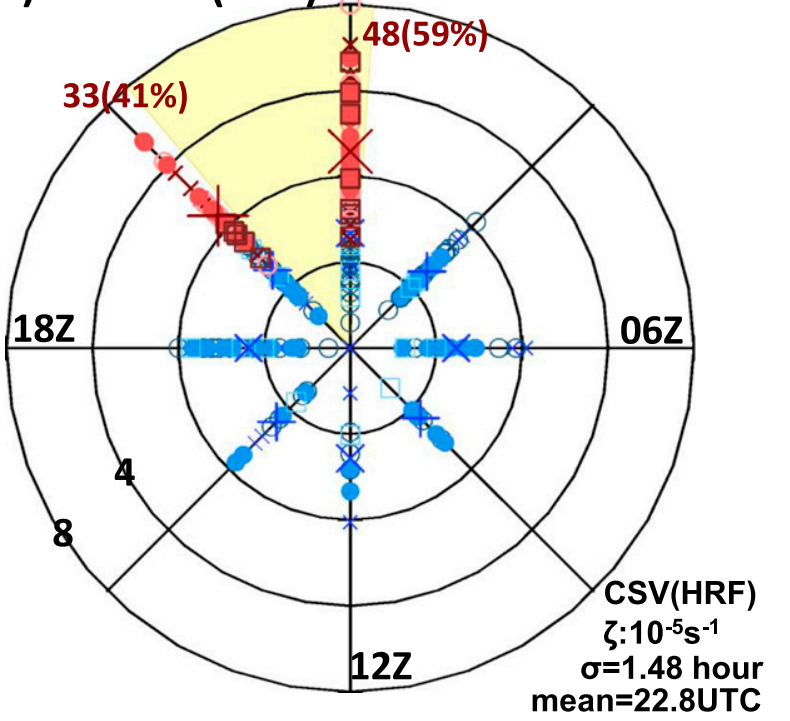

(c) $\left|\Delta p_{s}\right|$

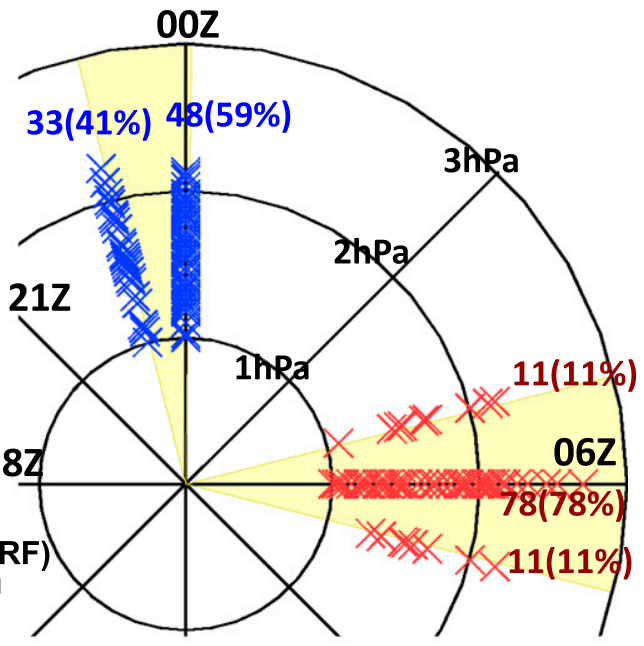

(a)

CSV (HRF) CSV(HRF) $\times$ Borneo

$\mathrm{X}$ CV

$\square$ PM

NP

O SP

$\triangle \mathrm{PS}$

CSV(NOD) $X \mathrm{BM}$

$\mathrm{X} C \mathrm{~B} \square \mathrm{BO}$

$\square \mathrm{PM}: \mathrm{JV}$

- NP

O SP

FIG. 9. (a) The formation time of the Philippine CSV(HRF) determined with the maximum vorticity of this vortex depicted by the streamline chart of the GEOS-53-h reanalysis, and (b) the formation time of CSV(HRF) in Borneo. (c) Formation times of CSV(HRF) in both the vicinity of the Philippines and Borneo are determined by the departure of the minimum $p_{s}$ from the daily-mean $p_{s}$ at the surface station closest to the vortex center.

a. Regulation of the CSV(HRF) propagation property by the cold surge flow type

\section{1) Demarcation Line of THE CSV(HRF) PROPAGATION PROPERTIES}

To determine the propagation activity of CSV(HRF), a demarcation line in the South China Sea is defined to divide CSV(HRF) into two groups-westward propagating and stagnant. Then, two sets of simple $(u, v)$ at $925 \mathrm{hPa}$ scatter diagrams of cold surge flow are presented to illustrate how these two types of cold surge flows affect the propagation properties for nine groups of $\mathrm{CSV}(\mathrm{HRF})$.

\section{(i) Definition of the propagation demarcation line}

The following steps are adopted to define this demarcation line in the South China Sea:

1) Indicated by the longitude-time diagram of its $\zeta(925 \mathrm{hPa})$ center, a CSV(HRF) reduces the westward propagation speed until its $\zeta(925 \mathrm{hPa})$ and $\zeta_{t}(925 \mathrm{hPa})$ centers spatially coincide. Register the time and location [solid triangle with color corresponding to the location of the associated cold surge's maximum $v(925 \mathrm{hPa})$ ] for this coincidence (Fig. 11a). 

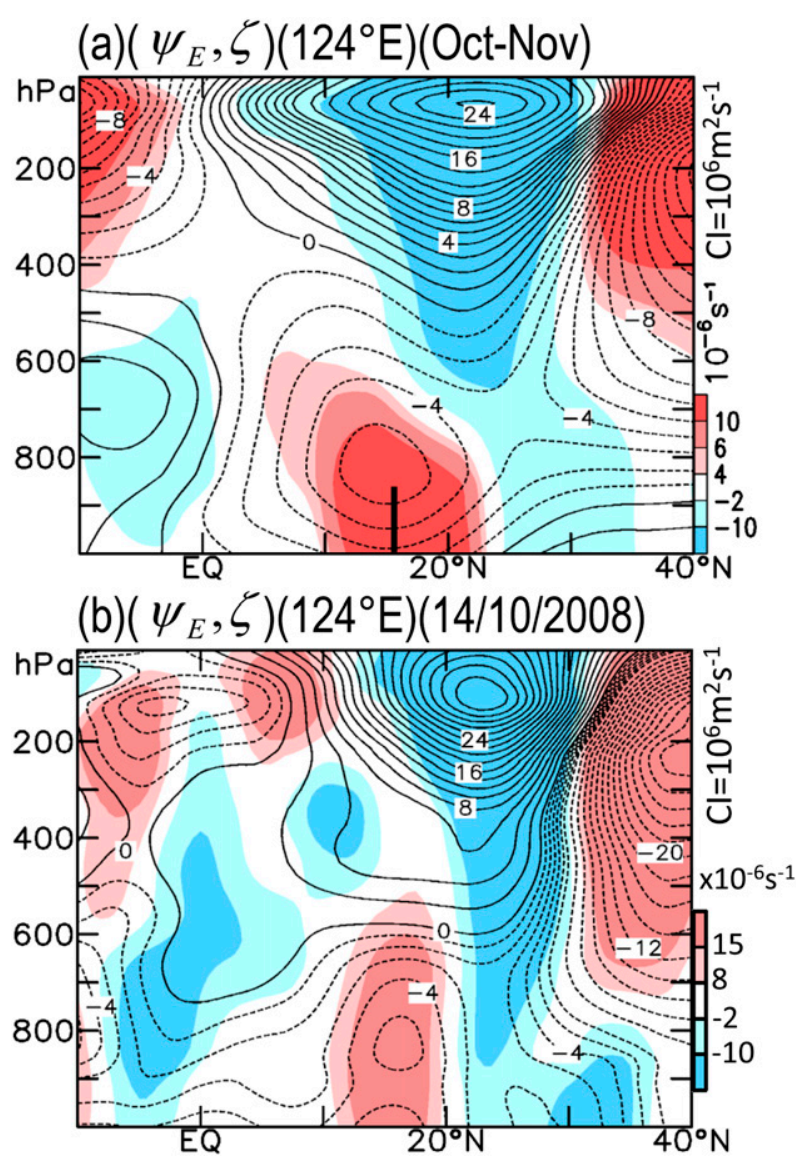

FIG. 10. (a) The latitude-height cross section of the OctoberNovember eddy streamfunction ( $\psi_{E}$; contour) superimposed with vorticity $\left(\zeta\right.$; color in red/blue) at $120^{\circ}$ E averaged over 1979-2012. The location of the island-chain trough is indicated by the thick tick mark at the bottom center. (b) As in (a), but for a CSV(HRF) formed in the vicinity of the Philippines on 14 Oct 2008 and propagated to central Vietnam.

2) Identify the location of the associated cold surge flow's maximum speed $|\mathbf{V}(925 \mathrm{hPa})|$ in the South China Sea, when the CSV(HRF) stops its westward propagation observed in step 1.

3) Register all identified locations of the cold surge flow's maximum speed in step 2 with crosses in Fig. 11a for all 98 stagnant CSV(HRF) (Table 2). The demarcation line between the westward-propagating and stagnant $\mathrm{CSV}(\mathrm{HRF})$ is defined by the mean-longitudinal locations of maximum $v(925 \mathrm{hPa})$ of the associated SCStype cold surge flows.

(ii) Scatter diagrams of the $(u, v)$ components at $925 \mathrm{hPa}$ at the location of maximum cold surge flow for both westward-propagating and stagnant CSV $(H R F)$

Locations of maximum cold surge flow speed are registered when $\operatorname{CSV}(\mathrm{HRF})$ centers for the five westward propagation groups (Table 2) reach the propagation demarcation line. The positive $\zeta_{t}(925 \mathrm{hPa})$ centers for CSV(HRF) are west of their positive $\zeta(925 \mathrm{hPa})$ centers. The $(u, v)$ components at $925 \mathrm{hPa}$ of the identified locations of maximum cold surge flow speed for these groups of CSV(HRF) are shown in the scatter diagrams (Fig. 11b). On the other hand, the scatter diagrams for $(u, v)$ at $925 \mathrm{hPa}$ at locations of maximum cold surge flow speed for the four stagnated/trapped CSV(HRF) groups at the propagation demarcation line are shown in the scatter diagrams in Fig. 11c. A positive $\zeta_{t}(925 \mathrm{hPa})$ center for CSV(HRF) coincides with its $\zeta(925 \mathrm{hPa})$ center.

The following salient features characterize these two sets of $(u, v)$ at $925 \mathrm{hPa}$ scatter diagrams:

1) For all westward-propagating CSV(HRF) (Fig. 11b), the $u(925 \mathrm{hPa})$ components for maximum cold surge flow speed (left-hand panel) are easterlies, while the accompanying $v(925 \mathrm{hPa})$ components (right-hand panel) are northerlies. The magnitude $u(925 \mathrm{hPa})$ for every identified maximum cold surge flow speed is larger than $v(925 \mathrm{hPa})$. The cold surge flow that allows CSV(HRF) to propagate westward across the propagation demarcation line is the PHS type.

2) For the stagnant CSV(HRF) (Fig. 11c), the $u(925 \mathrm{hPa})$ components of the maximum cold surge flow speed associated with these CSV(HRF) (left-hand panel) are all easterlies, while the $v(925 \mathrm{hPa})$ components (righthand panel) are all northerlies. The magnitude for the latter component is larger than the former. All cold surges concerned here are the SCS type.

\section{2) Composite (V, $|\mathbf{V}|)$ AT 925-HPA STREAmline CHARTS WHEN CSV(HRF) FORM}

To obtain a better perspective of how the cold surge flow patterns regulate the CSV(HRF) propagation property, the composite $(\mathbf{V},|\mathbf{V}|)$ at $925 \mathrm{hPa}$ streamline charts for nine groups of CSV(HRF) are shown in Figs. 12a-i (the statistical significances for all nine composite streamline charts are shown in second part of the supplemental material). Salient features for these composite streamline charts are:

(i) Despite formation locations for all five groups of westward-propagating CSV(HRF), the composite flow patterns (Figs. 12a-e) exhibit the PHS-type cold surge flow pattern with strong easterlies across the South China Sea.

(ii) The composite flow patterns for all four groups of stagnant CSV(HRF) (Figs. 12f-i) are characterized by strong northerlies of the SCS-type cold surge.

The strong easterly flow for the first five groups of CSV(HRF) facilitates the westward propagation of these vortices, while the strong northerly flow for the 
(a) Demarcation line of propagation

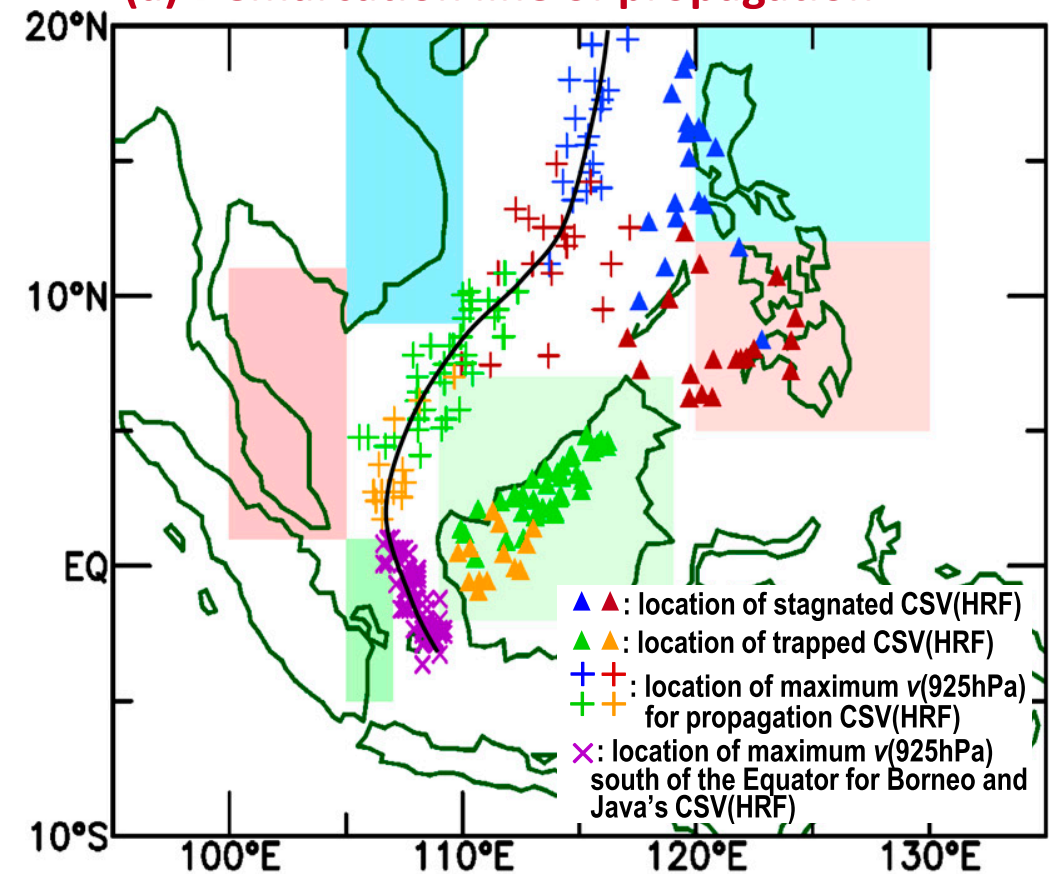

(b) propagation

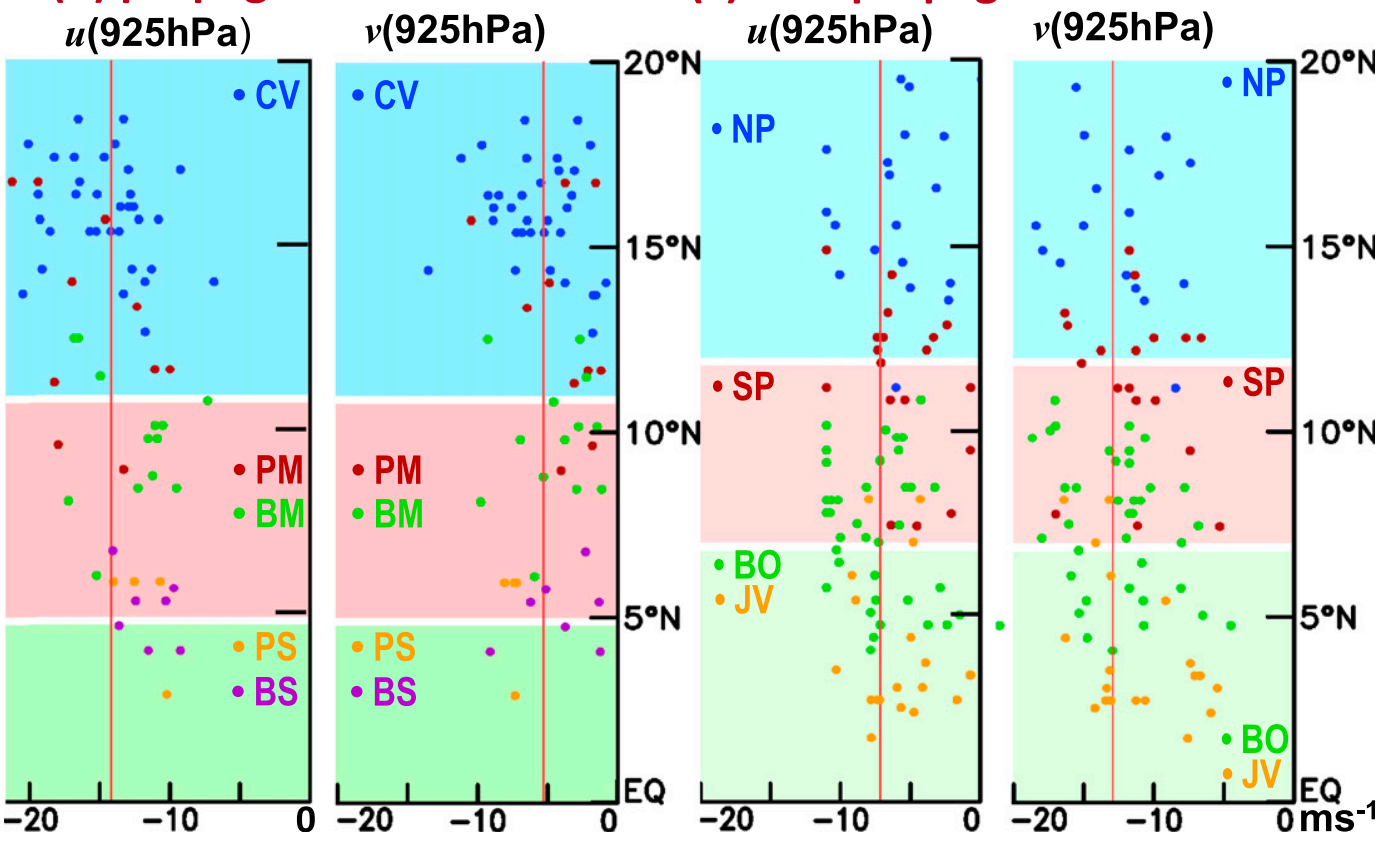

FIG. 11. (a) Location of CSV(HRF) trapped by the cold surge flow in the South China Sea is marked by a triangle, while the location of the maximum northerly of the associated cold surge flow is denoted by a cross. Then, the polynomial least squares fit with the cubic (third degree) function (Kincaid and Cheney 2002) is adopted to generate the demarcation line of propagation vs nonpropagation CSV(HRF). A black solid line depicts this demarcation line. (b) When centers of five groups of westward propagating CSV(HRF) reach the demarcation line, the maximum zonal and meridional wind speeds for this cold surge flow in the South China Sea are presented. (c) The 925-hPa zonal and meridional wind speeds of cold surge at the maximum northerly location for four groups of trapped CSV(HRF). Uppercase characters shown in both sides of (b) are the abbreviations: CV (Philippines-central Vietnam), PM (Philippines-Malaysia), BM (Borneo-Malaysia), PS (Philippines-southeastern Sumatra), and BS (Borneosoutheastern Sumatra), while abbreviations in (c) are NP (Philippine Sea-northern Philippines), SP (Philippine Seasouthern Philippines), BO (Borneo in situ), and JV [Java with Borneo CSV(HRF)]. 

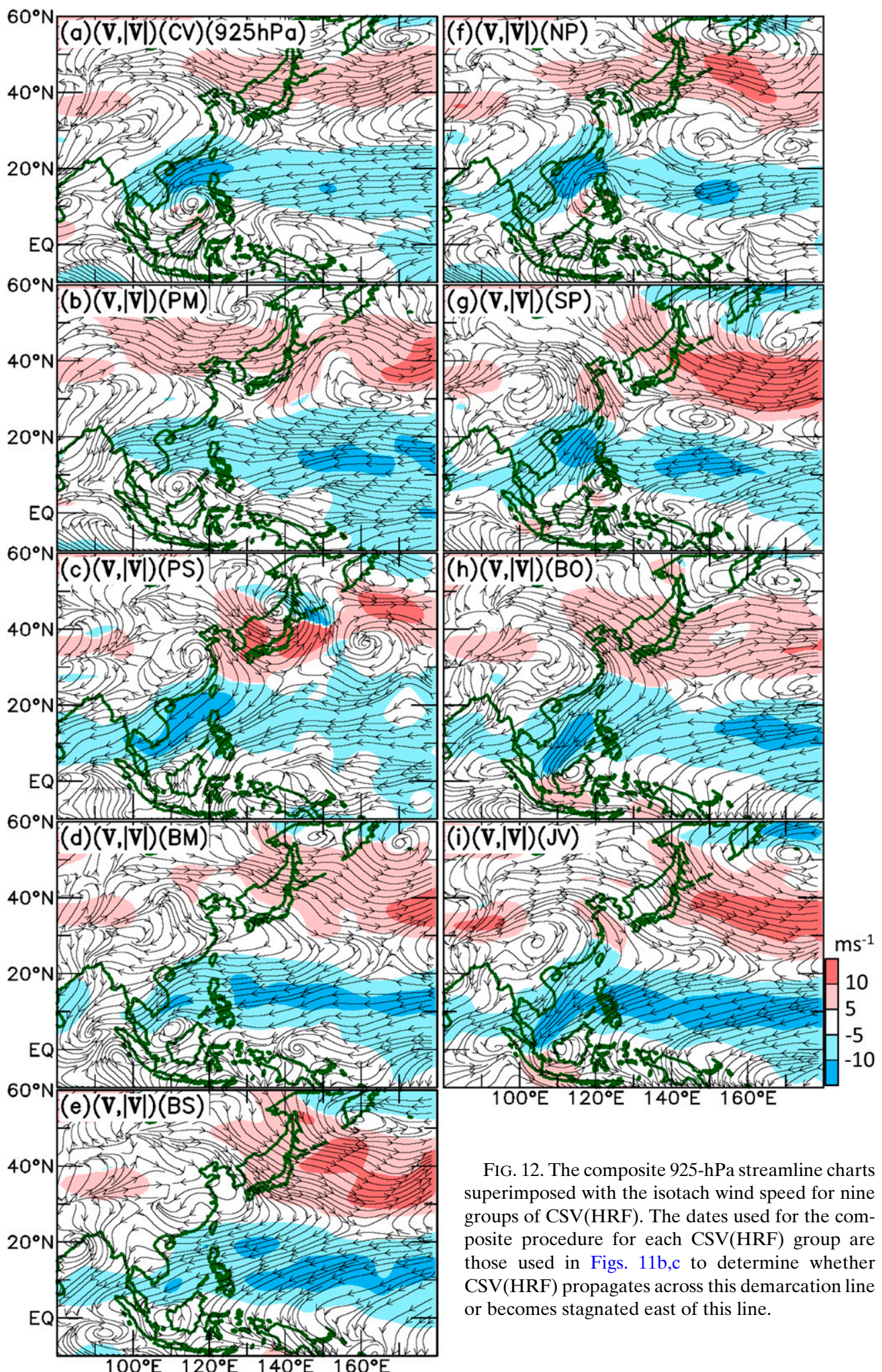

FIG. 12. The composite 925-hPa streamline charts superimposed with the isotach wind speed for nine groups of CSV(HRF). The dates used for the composite procedure for each $\mathrm{CSV}(\mathrm{HRF})$ group are those used in Figs. 11b,c to determine whether $\mathrm{CSV}(\mathrm{HRF})$ propagates across this demarcation line or becomes stagnated east of this line. 


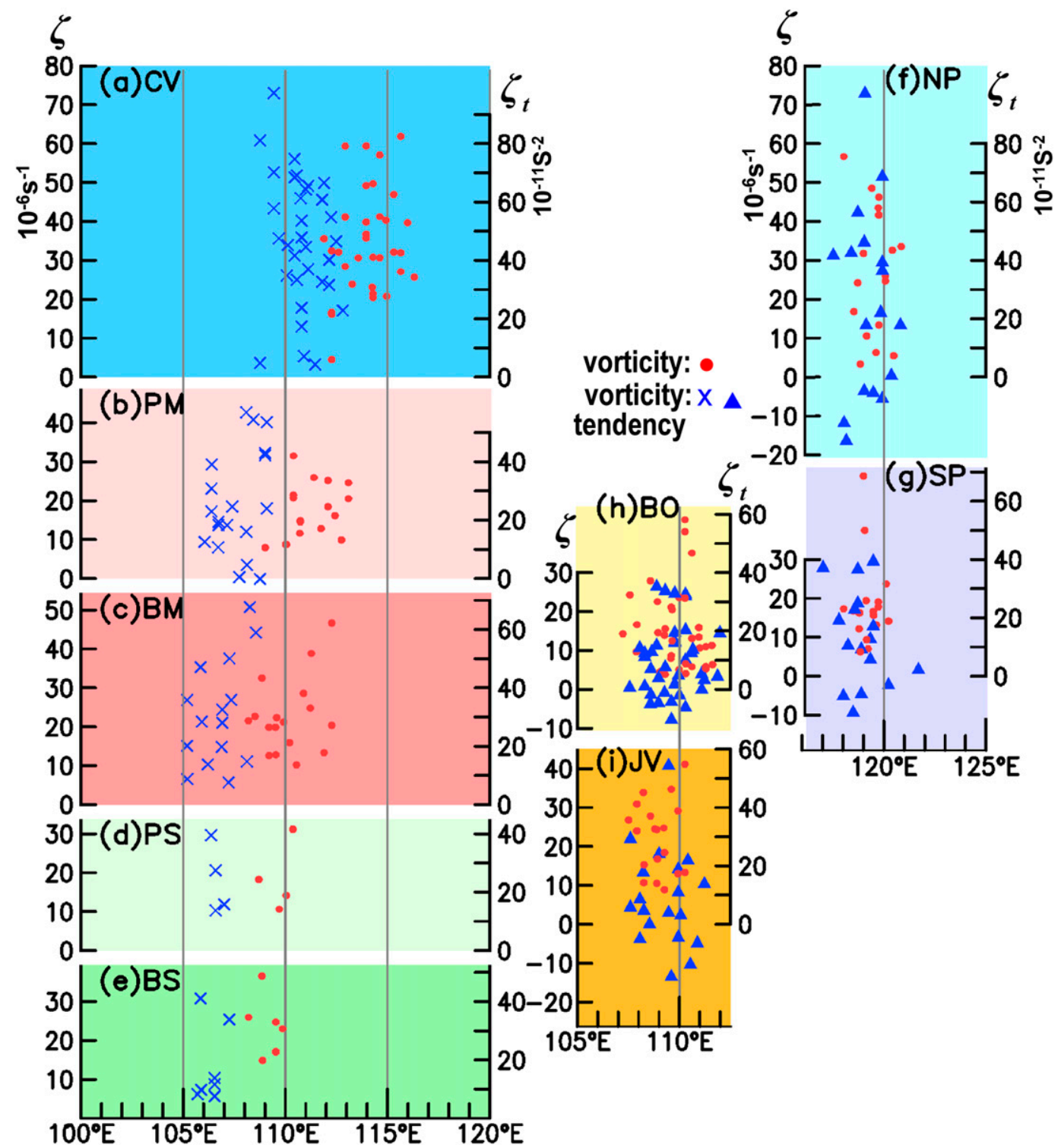

FIG. 13. (a)-(i) The center location of vorticity ( $\zeta$; red dots) vs that of vorticity tendency [ $\zeta_{t}$; blue crosses in (a)-(e) and triangles in (f)-(i)] for nine CSV(HRF) groups. Dates of CSV(HRF) processed for this figure are exactly the same as in Figs. 11b,c.

second four groups of CSV(HRF) prevents them from propagating westward. The cold surge flow type determines the steering mechanisms for these two groups of CSV(HRF).

\section{b. Vorticity budget analysis}

\section{1) Statistics of $\left(\zeta, \zeta_{t}\right)$ AT $925 \mathrm{HPA}$}

According to the vorticity budget equation, the total vorticity tendency is caused by the imbalance among the dynamic processes included. The spatial relationship between vorticity and its tendency center is used to illustrate the propagation property of a weather disturbance. This approach, adopted by Chen et al. (2013a), discloses the mechanism, which allows Borneo CSV(HRF) to propagate westward or become stagnant. Statistics of the spatial relationship between $\zeta(925 \mathrm{hPa})$ and $\zeta_{t}(925 \mathrm{hPa})$ are shown in Figs. 13a-i, when $\operatorname{CSV}(\mathrm{HRF})$ reach the demarcation line of propagation (Fig. 11a). The scatter diagrams for $\zeta(925 \mathrm{hPa})$ (red dots) and $\zeta_{t}(925 \mathrm{hPa})$ (blue crosses) centers on five PHS CSV(HRF) groups shown in Figs $13 \mathrm{a}-\mathrm{e}$, while $\zeta(925 \mathrm{hPa})$ (red dots) and $\zeta_{t}(925 \mathrm{hPa})$ (blue triangles) for four SCS CSV(HRF) groups are 


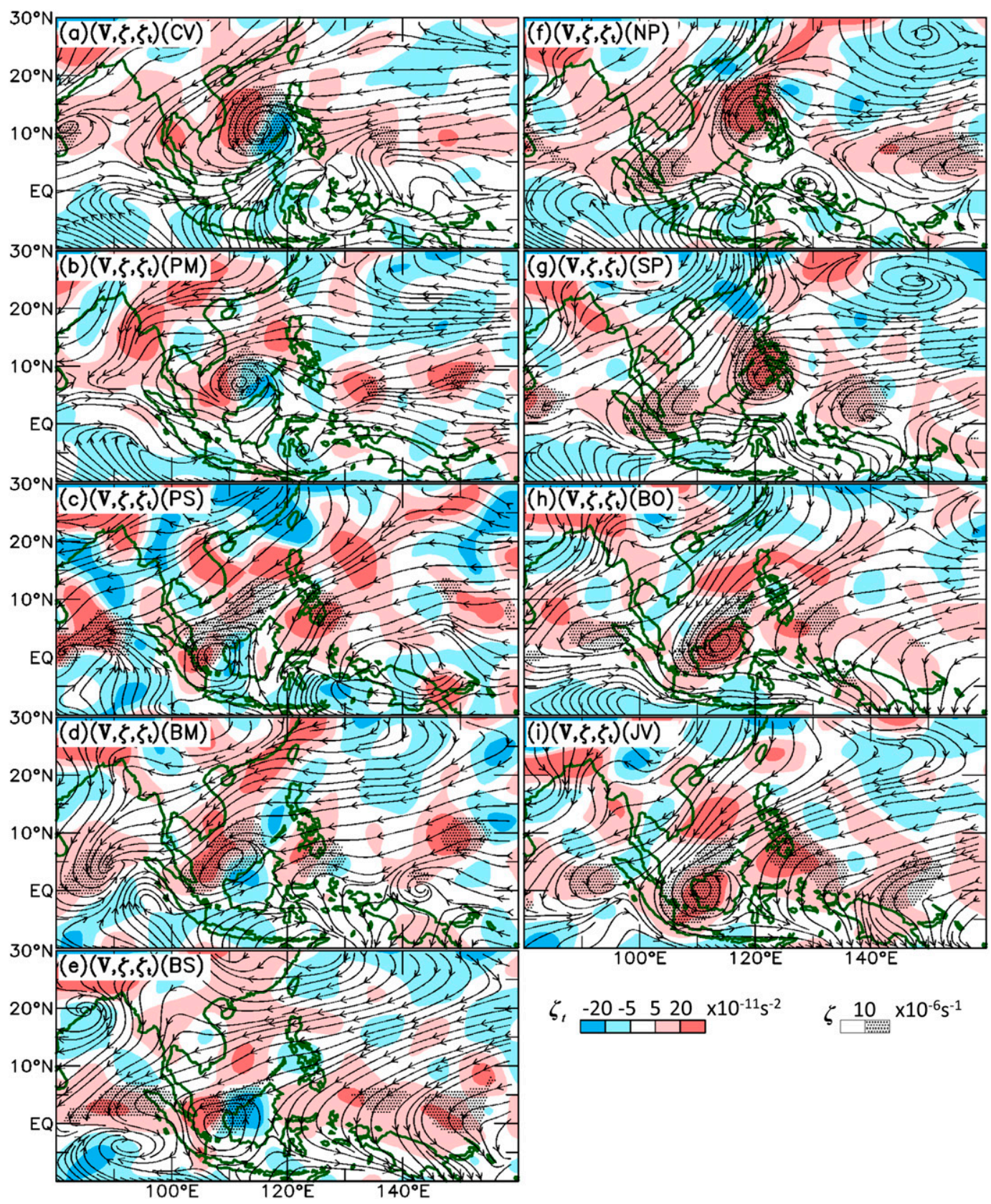

FIG. 14. As in Fig. 12, except the composite streamline chart is superimposed with vorticity ( $\zeta$; shading) and vorticity tendency $\left(\zeta_{i}\right.$; red and blue colors) at $925 \mathrm{hPa}$. The composite procedure for this figure is the same as in Fig. 12.

displayed in Figs. $13 \mathrm{f}-\mathrm{i}$. The $\zeta_{t}(925 \mathrm{hPa})$ centers for five former $\operatorname{CSV}(\mathrm{HRF})$ groups are west of the corresponding $\zeta(925 \mathrm{hPa})$ centers, while those for four latter CSV(HRF) groups are spatially in phase with the corresponding $\zeta(925 \mathrm{hPa})$ centers. The spatial relationship between the $\zeta_{t}(925 \mathrm{hPa})$ and $\zeta(925 \mathrm{hPa})$ centers for the first five groups allows each CSV(HRF) to propagate westward, but not for any in the second four groups.

\section{2) Composite charts of $(\mathbf{V}, \zeta, \zeta$ ) AT $925 \mathrm{HPA}$}

Following Figs. 12a-i, the composite $925-\mathrm{hPa}$ streamline charts for nine groups of parent CSV(HRF) superimposed with $\left(\zeta, \zeta_{t}\right)$ at $925 \mathrm{hPa}$ are shown in Figs. 14a-i (the statistical significances for all nine streamline charts are shown in the second part of the supplemental material). The positive $\zeta_{t}(925 \mathrm{hPa})$ centers appear west of the $\zeta(925 \mathrm{hPa})$ centers for five groups of 
parent CSV(HRF) [when they form over the Philippine Sea and Borneo (Figs. 14a-e)] to develop HRF cyclones/ events in the three rainfall centers west of the South China Sea. In contrast, positive $\zeta_{t}(925 \mathrm{hPa})$ and $\zeta(925 \mathrm{hPa})$ centers spatially coincide with the CSV(HRF) centers for all four groups of CSV(HRF) formations east of the South China Sea (Figs. 14f-i). CSV(HRF) for these four groups can develop, but cannot propagate. The vorticity budget for the five groups of westward-propagating CSV(HRF) reveals the positive $\zeta_{t}(925 \mathrm{hPa})$ centers west of the $\zeta(925 \mathrm{hPa})$ centers of these vortices are primarily contributed by total vorticity advection, driven primarily by strong easterlies from the PHS-type cold surge flow. For those nonpropagating CSV(HRF), the stagnation of these vortices is attributed to vortex stretching by the lowlevel convergence of these CSV(HRF). To save space, $\zeta_{t}(925 \mathrm{hPa})$ contributed by both vorticity advection and vortex stretching for both westward-propagating and stagnant in situ CSV(HRF) are posted online (http://eamex.iastate.edu/publication/vorticity_budget_ 181HRF.pdf).

\section{Concluding remarks}

Cheang (1977) suggested the peninsular Malaysia HRF event is formed by the interaction of easterly waves with the cold surge flow. Yokoi and Matsumoto (2008) showed the occurrence of the central Vietnam HRF event requires the presence of a cold surge flow. Recently, Chen et al. $(2012 b, c)$ demonstrated the formation of the central Vietnam HRF occurs when the three monsoon modes (30-60,10-20, and 5 day) exhibit constructive in-phase interference, and also synchronizes with the occurrence of the northwestern Pacific explosive cyclone. The current study determined the development of CSV(HRF) and their corresponding HRF cyclones/events are more complex than previously understood. According to Fig. 1, there are seven heavy rainfall centers around the east and west coasts of the South China Sea. In total, 181 HRF events during the 1979-2012 period were identified by DFO over these rainfall centers. Backtracking these HRF events along their trajectories to the formation location of their parent CSV(HRF), three important aspects about the development mechanisms of both CSV(HRF) and HRF cyclones/events are disclosed: 1) the formation mechanism of CSV(HRF), 2) propagation properties of $\operatorname{CSV}(\mathrm{HRF})$, and 3) the development mechanism of HRF cyclones/events. Because of the research scope for this study, our findings are reported in two parts-the first two aspects found herein are summarized below, while the third aspect will be reported in Part II.
The new findings regarding the formation mechanism and propagation properties are summarized here.

\section{a. Formation mechanism of CSV $(H R F)$}

\section{1) PReferred TyPe of COLd SURGE Flow}

Two CSV(HRF) formation mechanisms are identified through Figs. 4, 6, and 7, and summarized in Tables 3 and 4:

- Philippine CSV(HRF) are formed by the interactions of easterly waves with the PHS-type cold surge flow and the surface island-chain trough.

- Borneo CSV(HRF) are generated by the interactions of the SCS-type cold surge flow with Borneo orography and cyclonic shear flow around the near-equator trough.

\section{2) GEOGRAPHIC PREFERENCE}

Synoptically, the formation of Philippine and Borneo $\mathrm{CSV}(\mathrm{HRF})$ requires the surface island-chain trough and the near-equator trough, respectively. The former trough appears east of the Philippines, across Taiwan to southern Japan, while the latter trough exists across Borneo. Thus, these two troughs facilitate the formation of these two groups of CSV(HRF) in the vicinity of the Philippines and Borneo, respectively, as summarized in Fig. 8.

\section{3) PREFERRED Formation TIME OF DAY}

A great majority ( $\sim 78 \%$ ) of the Philippine CSV(HRF) forms at 0600 UTC, whereas the Borneo CSV(HRF) form during a window between 2100 and 0000 UTC. These observations are summarized in Fig. 9. The former CSV(HRF) form when the minimum semidiurnal $p_{s}$ component propagates across the Philippines to trigger deep convection in the afternoon. In contrast, the latter CSV(HRF) form when the morning cold downslope flow of Borneo collides with the SCS-type cold surge flow-the Houze et al. (1981) mechanism.

\section{b. Propagation properties of CSV $(H R F)$}

Indicated by trajectories between HRF events and their parent CSV(HRF) in Figs. 2a-c, both Philippine and Borneo CSV(HRF) can propagate westward across the South China Sea and develop into HRF events in the three rainfall centers (central Vietnam, peninsular Malaysia, and southeastern Sumatra) west of the South China Sea. In contrast, some of these two groups of CSV(HRF) in Figs. 2d and 2e become stagnated over the four rainfall centers (northern and southern Philippines, Borneo, and Java) east and south of the South China Sea. These two propagation properties are shown in Figs. 11 and 12. The vorticity budget analysis shows the PHS-type (SCS type) of cold surge flow facilitates 
(hinders) the westward propagation of CSV(HRF) across the South China Sea (Figs. 13 and 14).

Without comparing the CSV(HRF) formation and propagation activity over the countries around the South China Sea, it is difficult, if not impossible, to find these crucial factors determining the formation and propagation mechanisms of CSV(HRF). This approach provides a more in-depth perspective for these mechanisms, but new findings also lead us to raise the following issues for future research efforts:

1) The geographic preference for CSV(HRF) formation is affected by locations of both the island-chain surface and the near-equator troughs. How does the climatology of these two troughs affect the daily synoptic development of these two troughs? What roles do these two troughs play in the winter monsoon circulation? How does the ENSO cycle affect the activity of HRF events through these two troughs?

2) The diurnal variation of atmospheric circulation/ weather systems has not been well simulated or forecasted by either regional or global models for climate and weather forecasts around the South China Sea (e.g., Gianotti et al. 2012). This possible model bias may need a serious effort to improve the modeling for both diurnal and semidiurnal modes.

3) The nighttime radiative cooling and convective/ stratiform rainfall (Wu et al. 2008) over the central Borneo mountains have not been well explored. Accurate forecasts of the Borneo CSV(HRF) formation need some effort to explore the orography cooling and convection over Borneo.

4) The flow types of cold surge within the South China Sea primarily determine the formation mechanism of the Philippine and Borneo CSV(HRF), and their propagation properties. These flow types are primarily determined by the midlatitudes-tropic interaction, but the performance of operational models for the winter monsoon, particularly this interaction, has not attracted much research attention.

Acknowledgments. The Cheney Research Fund and NSF Grant ATM-0836220 sponsored this study. Jun Matsumoto's contribution to this study is supported by the Grant-in-Aid for Scientific Research (26220202) from the Japan Society for the Promotion of Science. Comments and suggestions offered by two anonymous reviewers were very helpful in improving the presentation of this study.

\section{REFERENCES}

Blersch, D. J., and T. C. Probert, 1991: Geostationary meteorological satellite systems-An overview. J. Pract. Appl. Space, 2,1-13.
Cheang, B. K., 1977: Synoptic features and structures of some equatorial vortices over the South China Sea in the Malaysian region during the winter monsoon, December 1973. Pure Appl. Geophys., 115, 1303-1333, doi:10.1007/BF00874411.

Chen, T.-C., 2002: A North Pacific short-wave train during the extreme phases of ENSO. J. Climate, 15, 2359-2376, doi:10.1175/ 1520-0442(2002)015<2359:ANPSWT $>2.0 . C O ; 2$.

- 2005: The structure and maintenance of stationary waves in the winter Northern Hemisphere. J. Atmos. Sci., 62, 36373660, doi:10.1175/JAS3566.1.

_ J.-D. Tsay, M.-C. Yen, and J. Matsumoto, 2012a: Interannual variation of the late fall rainfall in central Vietnam. J. Climate, 25, 392-413, doi:10.1175/JCLI-D-11-00068.1.

— M.-C. Yen, J.-D. Tsay, J. Alpert, and N. T. T. Thanh, 2012b: Forecast advisory for the late fall heavy rainfall/flood event in central Vietnam developed from diagnostic analysis. Wea. Forecasting, 27, 1155-1177, doi:10.1175/WAF-D-11-00104.1.

,,,--- N. T. T. Thanh, and J. Alpert, 2012c: Synoptic development of the Hanoi heavy rainfall event during 30-31 October 2008: Multiple-scale processes. Mon. Wea. Rev., 140, 1219-1240, doi:10.1175/MWR-D-11-00111.1.

_ J.-D. Tsay, M.-C. Yen, and J. Matsumoto, 2013a: The winter rainfall of Malaysia. J. Climate, 26, 936-958, doi:10.1175/ JCLI-D-12-00174.1.

,,,--- and,$- 2013 \mathrm{~b}$ : Interannual variation of the winter rainfall in Malaysia. J. Climate, 26, 4630-4648, doi:10.1175/ JCLI-D-12-00367.1.

—, , and J. Matsumoto, 2015: Development and formation mechanism of the Southeast Asian winter heavy rainfall events around the South China Sea. Part II: Multiple interactions. J. Climate, 28, 1444-1464, doi:10.1175/JCLI-D-14-00171.1.

Compo, G. P., G. N. Kiladis, and P. J. Webster, 1999: The horizontal and vertical structure of East Asian winter monsoon pressure surges. Quart. J. Roy. Meteor. Soc., 125, 29-54, doi:10.1002/qj.49712555304.

Dee, D. P., and Coauthors, 2011: The ERA-Interim reanalysis: Configuration and performance of the data assimilation system. Quart. J. Roy. Meteor. Soc., 137, 553-597, doi:10.1002/qj.828.

DFO, 2013: Global active archive of large flood events. Dartmouth Flood Observatory. [Available online at http://floodobservatory. colorado.edu/.]

EM-DAT, 2013: The international disaster database. Center for Research on the Epidemiology of Disasters. [Available online at http://www.emdat.be/.]

Gianotti, R. L., D. Zhang, and E. A. B. Eltahir, 2012: Assessment of the Regional Climate Model version 3 over the Maritime Continent using different cumulus parameterization and land surface schemes. J. Climate, 25, 638-656, doi:10.1175/JCLI-D-11-00025.1.

Houze, R. A., S. G. Geotis, F. D. Marks, and A. K. West, 1981: Winter monsoon convection in the vicinity of north Borneo. Part I: Structure and time variation of the clouds and precipitation. Mon. Wea. Rev., 109, 1595-1614, doi:10.1175/ 1520-0493(1981)109<1595:WMCITV>2.0.CO;2.

Huffman, G. J., and D. T. Bolvin, 2013: Version 1.2 GPCP onedegree daily precipitation data set documentation. GPCP. [Available online at ftp://rsd.gsfc.nasa.gov/pub/1dd-v1.2/ 1DD_v1.2_doc.pdf.]

Kanamitsu, M., and Coauthors, 1991: Recent changes implemented into the global forecast system at NMC. Wea. Forecasting, 6, 425435, doi:10.1175/1520-0434(1991)006 <0425:RCIITG $>2.0$.CO;2.

Kincaid, D., and W. Cheney, 2002: Numerical Analysis: Mathematics of Scientific Computation. 3rd ed. American Mathematical Society, $788 \mathrm{pp}$. 
Lindzen, R. S., 1971: Tides and gravity waves in the upper atmosphere. Mesospheric Models and Related Experiments, G. Fiocco, Ed., D. Reidel, 122-130.

Meteorological Services Centre Japan, 1997: GMS-5 User's Guide. 3rd ed. Meteorological Satellite Center of Japan, 190 pp.

Nitta, T., and S. Sekine, 1994: Diurnal variation of convective activity over the tropical western Pacific. J. Meteor. Soc. Japan, 72, 627-641.

Reynolds, R. W., N. A. Rayner, T. M. Smith, D. C. Stokes, and W. Wang, 2002: An improved in situ and satellite SST analysis for climate. J. Climate, 15, 1609-1625, doi:10.1175/ 1520-0442(2002)015<1609:AIISAS > 2.0.CO;2.

Rienecker, M. M., and Coauthors, 2008: The GEOS-5 Data Assimilation System-Documentation of versions 5.0.1 and 5.1.0. NASA GSFC Technical Report Series on Global Modeling and Data Assimilation, Vol. 27, NASA/TM-2007-104606, 118 pp.

Sanders, F., and J. R. Gyakum, 1980: Synoptic-dynamic climatology of the "bomb". Mon. Wea. Rev., 108, 1589-1606, doi:10.1175/ 1520-0493(1980)108<1589:SDCOT>2.0.CO;2.

Simpson, J., C. Kummerow, W. K. Tao, and R. F. Adler, 1996: On the Tropical Rainfall Measuring Mission (TRMM). Meteor. Atmos. Phys., 60, 19-36, doi:10.1007/BF01029783.

Spencer, R. W., 1993: Global oceanic precipitation from the MSU during 1979-91 and comparisons to other climatologies.
J. Climate, 6, 1301-1326, doi:10.1175/1520-0442(1993)006<1301: GOPFTM $>2.0 . \mathrm{CO} ; 2$

Susskind, J., P. Piraino, L. Rokke, L. Iredell, and A. Mehta, 1997: Characteristics of the TOVS Pathfinder Path A dataset. Bull. Amer. Meteor. Soc., 78, 1449-1472, doi:10.1175/ 1520-0477(1997)078<1449:COTTPP >2.0.CO;2.

Wu, P., D. M. Yamanaka, and J. Matsumoto, 2008: The formation of nocturnal rainfall offshore from convection over western Kalimantan (Borneo) Island. J. Meteor. Soc. Japan, 86, 187203, doi:10.2151/jmsj.86A.187.

Yang, F., H.-L. Pan, S. K. Krueger, S. Moorthi, and S. J. Lord, 2006: Evaluation of the NCEP Global Forecast System at the ARM SGP site. Mon. Wea. Rev., 134, 3668-3690, doi:10.1175/ MWR3264.1.

Yatagai, A., K. Kamiguchi, O. Arakawa, A. Hamada, N. Yasutomi, and A. Kitoh, 2012: APHRODITE: Constructing a long-term daily gridded precipitation dataset for Asia based on a dense network of rain gauges. Bull. Amer. Meteor. Soc., 93, 14011415, doi:10.1175/BAMS-D-11-00122.1.

Yokoi, S., and J. Matsumoto, 2008: Collaborative effects of cold surge and tropical depression-type disturbance on heavy rainfall in central Vietnam. Mon. Wea. Rev., 136, 3275-3287, doi:10.1175/2008MWR2456.1. 